\title{
An Evaluation of Satellite Remote Sensing Data Products for Land Surface Hydrology: Atmospheric Infrared Sounder*
}

\author{
CRAIG R. FERGUSON AND ERIC F. WOOD \\ Department of Civil and Environmental Engineering, Princeton University, Princeton, New Jersey
}

(Manuscript received 15 September 2009, in final form 31 March 2010)

\begin{abstract}
The skill of instantaneous Atmospheric Infrared Sounder (AIRS) retrieved near-surface meteorology, including surface skin temperature $\left(T_{s}\right)$, air temperature $\left(T_{a}\right)$, specific humidity $(q)$, and relative humidity $(\mathrm{RH})$, as well as model-derived surface pressure $\left(P_{\text {surf }}\right)$ and $10-\mathrm{m}$ wind speed $(w)$, is evaluated using collocated National Climatic Data Center (NCDC) in situ observations, offline data from the North American Land Data Assimilation System (NLDAS), and geostationary remote sensing (RS) data from the Spinning Enhanced Visible and Infrared Imager (SEVIRI). Such data are needed for RS-based water cycle monitoring in areas without readily available in situ data. The study is conducted over the continental United States and Africa for a period of more than 6 years (2002-08). For both regions, it provides for the first time the geographic distribution of AIRS retrieval performance. Through conditional sampling, attribution of retrieval errors to scene atmospheric and surface conditions is performed. The findings support previous assertions that performance degrades with cloud fraction and that (positive) bias enhances with altitude. In general AIRS is biased warm and dry. In certain regions, strong AIRS-NCDC correlation suggests that bias-driven errors, which can be substantial, are correctable. The utility of the error characteristics for prescribing the inputinduced uncertainty of RS retrieval models is demonstrated through two applications: a microwave soil moisture retrieval algorithm and the Penman-Monteith evapotranspiration model. An important side benefit of this study is the verification of NLDAS forcing.
\end{abstract}

\section{Introduction}

Improving our ability to observe, understand, and model regional and global atmospheric and terrestrial water and energy cycles is an unresolved objective of the World Climate Research Programme (WCRP) Global Energy and Water Cycle Experiment (GEWEX). Once limited by a scarcity of land surface observations, water and energy budget studies now have access to a multitude of satellite remote sensing (RS)-derived datasets, including surface skin temperature ( $T_{s}$; Holmes et al. 2009), soil moisture (SM; Gao et al. 2006; Lu et al. 2009; Njoku et al. 2003), precipitation ( $P$; Hsu et al. 1997; Hsu et al. 1999; Huffman et al. 2003; Sorooshian et al. 2000), runoff

\footnotetext{
* Supplemental information related to this paper is available at http://dx.doi.org/10.1175/2010JHM1217.s1.
}

Corresponding author address: Craig Ferguson, Department of Civil and Environmental Engineering, Princeton University, E-Quad, Rm. E-209A, Princeton, NJ 08544.

E-mail: cferguso@princeton.edu
( $Q$; Alsdorf et al. 2008; Birkett, 1998; Frappart et al. 2006), radiative fluxes (Stackhouse et al. 2000; Zhang et al. 2004), vegetative properties (Ganguly et al. 2008; F. Gao et al. 2008; Tucker et al. 2005), snow cover area (SCA; Hall et al. 2002), snowpack water equivalent (SWE; Kelly et al. 2003), terrestrial water storage (TWS; Tapley et al. 2004), and atmospheric temperature and humidity profiles (Susskind et al. 2003, 1997), available globally with temporal frequency of a few days to twice daily at spatial resolutions of $1-250 \mathrm{~km}$. The RS datasets offer an unprecedented potential of tightening constraints on terrestrial water and energy budgets [Eqs. (1)-(2)] through direct observations of $\Delta S, P, Q$, and $R_{n}$ and indirect (retrieved) estimates of $H, \lambda E$, and $G$, where $\Delta S$ is the change in TWS, $R_{n}$ is the net radiation flux, $H$ is the sensible heat flux, $\lambda$ is the latent heat of vaporization $\left(\lambda \approx 2.45 \mathrm{MJ} \mathrm{kg}^{-1}\right.$ at $\left.20^{\circ} \mathrm{C}\right), E$ is the evapotranspiration, and $G$ is the soil heat flux at the earth's surface:

$$
\begin{aligned}
& \Delta S=P-E-Q, \\
& R_{n}=H+\lambda E+G .
\end{aligned}
$$


For example, Ferguson et al. (2010) utilized the suite of sensors onboard the National Aeronautics and Space Administration (NASA) Earth Observing System (EOS) Aqua, including the Atmospheric Infrared Sounder/ Advanced Microwave Sounding Unit/Humidity Sounder Brazil (AIRS/AMSU/HSB, hereafter AIRS), the Clouds and Earth's Radiant Energy System (CERES), and the Moderate Resolution Imaging Spectroradiometer (MODIS) to estimate daily RS- $E$ over the continental United States (CONUS) at 5-km resolution. These RS- $E$ estimates were subsequently used by Sheffield et al. (2009), together with Gravity Recovery and Climate Experiment (GRACE; Tapley et al. 2004) $\Delta S$ and the Tropical Rainfall Measuring Mission (TRMM) Multisatellite Precipitation Analysis (TMPA; Huffman et al. 2007) or the Climate Prediction Center (CPC) morphing technique (CMORPH; Joyce et al. 2004) $P$, to demonstrate over the Mississippi River basin the feasibility of monitoring the terrestrial water budget exclusively with RS data. Feasibility was confirmed, but the water balance closure error was shown to be on the order of the basin's $Q$, underscoring basic inconsistency among current state-of-the-art RS products. Other studies have demonstrated significant improvements in the accuracy of numerical weather prediction (NWP) forecasts and land surface hydrology model outputs through data assimilation (DA) of one or several of the aforementioned RS datasets (Andersson et al. 2007; Andreadis and Lettenmaier 2006; Crow and Wood 2003; Margulis and Entekhabi 2003; Pan and Wood 2009; Reichle et al. 2008; Walker and Houser 2001). In the absence of a sufficient in situ network (e.g., Africa), NWPs and RS observations provide the only tools for hydrology.

Migrating from single process, single variable oriented approaches to synergistic frameworks, like DA, or the hydrological consistency approach of McCabe et al. (2008) that integrate several diverse variables is to exploit fully the information content of available RS observations. Such efforts culminate in value-added level 4 "knowledge" (Asrar and Dokken 1993) data products, of which $E$ is a primary example.

Over land, climate may be viewed as a complex balance of many highly coupled processes that collectively drive the exchanges of moisture and energy between soil, vegetation, and the overlying atmospheric planetary boundary layer (PBL; e.g., Betts et al. 1996; Dirmeyer 2006; Ek and Holtslag 2004; Shuttleworth 1988). Measurement of any number of these states, fluxes, or related variables, either concurrently or independently, at varying time steps and resolution as is often the reality with RS, provides an opportunity to establish confidence in the derived quantities through hydrological consistency. For example, for drought monitoring observations of low soil moisture alone may be insufficient because of the sensing depth $(1-3 \mathrm{~cm})$ and sampling (i.e., mixed pixels) limitations. Closely timed observations of zero $P$, low humidity, high $T_{s}$, and low $Q$, would improve the reliability of such monitoring (Luo and Wood 2007). Likewise, SM combined with $P$ (warm season) or SM combined with $P, T_{s}$, SCA, and SWE (cold season) should reduce flood forecasting errors (Bindlish et al. 2009; Crow et al. 2005; Hong et al. 2007; Kumar et al. 2008). Linked, derived products enable independent uncertainty estimates, as demonstrated for $P$ using SM (Crow and Bolten 2007), but the performance can benefit mutually (Crow et al. 2009).

That the land surface and atmospheric processes feedback on one another (i.e., coupling) has important implications for hydrologic intensification (see Huntington 2006) that may occur under a changing climate. Remote sensing offers the only viable method for quantifying through observation at regional to global scales, hydrologic sensitivity to climate change, including the strength of land-atmospheric coupling. The absence of an objective, multiseason, observation-based quantification of large-scale coupling strength has been recognized as a "major obstacle to the evaluation of model performance and development" (Guo et al. 2006). The GEWEX Global Land-Atmosphere Coupling Experiment (GLACE; Guo et al. 2006; Koster et al. 2006) called attention to distinct multimodel coupling "hot spots" located in the Sahel, the central Great Plains, India, and eastern Asia. To what extent are these spatial patterns of simulated coupling strength reflective of reality, and not just an artifact of the models (Koster et al. 2003)?

To truly address any of these issues requires that we first answer the following question: How well do we observe the underlying variables? Our current environment is characterized by an abundance of (RS) data that is of poorly quantified skill, a consequence of which is our present inability to prescribe meaningfully confidence limits to model outputs.

With these issues in mind, the aim of this paper is to validate "indirect" variables, including $T_{s}, 2$-m air temperature $\left(T_{a}\right)$, and humidity-both relative $(\mathrm{RH})$ and specific $(q)$, such that confidence in derived coupling diagnostics, $E$ and SM, for example, may be achieved. Historically, these variables have been undervalidated. We focus on the evaluation of AIRS, the most advanced atmospheric sounding system ever deployed in space (Chahine et al. 2006). Our analyses span a greater than 6-yr period (2002-08) over two highly diverse (both in climate and potential applicability) domains: CONUS and Africa. We evaluate the data against observations from more than 2000 ground stations from the National Climatic Data Center's (NCDC) Integrated Surface Database (ISD; Lott et al. 2001), offline data from the North 
American Land Data Assimilation System (NLDAS; Mitchell et al. 2004), and estimates of $T_{s}$ over Africa from the Meteorological Satellites (Meteosat) Second Generation's (MSG) Spinning Enhanced Visible and Infrared Imager (SEVIRI; Schmetz et al. 2002). We quantify retrieval accuracies over a broad range of surface and atmospheric conditions. Specifically along gradients in $T_{a}$ or $T_{s}$, cloud albedo $\left(\alpha_{\text {cloud }}\right)$, total column precipitable water vapor/ice (pwv), elevation, topographic (vertical) complexity (vc), land cover (lc) class, leaf area index (LAI), snow cover, and season. Using statistics of bias, random error, and nonparametric correlation, we map the distribution of mean retrieval accuracies and provide a summary of conditions for which we expect retrievals to be most and least skillful.

\section{Study domains and period}

We focus our analyses on two regions: the CONUS domain $\left(25^{\circ}-53^{\circ} \mathrm{N}, 125^{\circ}-67^{\circ} \mathrm{W}\right)$ and Africa $\left(40^{\circ} \mathrm{S}-40^{\circ} \mathrm{N}\right.$, $20^{\circ} \mathrm{W}-55^{\circ} \mathrm{E}$ ), which we hold to be global end members with respect to ground station network densities, and coincidentally the potential impact of RS data assimilation to weather forecast skill. CONUS boasts the highest-density openly available ground measurement network in the world, making it one of the most suitable domains for validating satellite-based near-surface variables. On the other hand, parts of Africa are the most data sparse in the world. Together, the two domains offer a large variety of retrieval conditions (in terms of both landscapes and climate) for which to evaluate retrieval accuracies. The total study period spans from September 2002 through December 2008, with two exceptions: 1) analyses using CERES-derived $\alpha_{\text {cloud }}$ are limited to September 2002-August 2007, and 2) analyses using SEVIRI $T_{s}$ are limited to July 2005-2009 (see section 3$)$. Only the ascending, or afternoon ( 1:30 p.m. local time) overpass, is considered. Daytime retrievals are both more challenging and valuable than similar nighttime measurements because they capture the effects of differential heating and evaporation, or surface water and energy fluxes, which we aim to help quantify and that may feedback on the atmosphere.

\section{Data and methods}

Table 1 provides an overview of the 13 data products used in this study. Because of space constraints, we refer the reader to Ferguson et al. (2010) for a description of the following datasets: 1) the National Centers for Environmental Prediction Global Forecast System (NCEP GFS) surface pressure [packaged with AIRS Level 2 Support Product Dataset (AIRX2SUP)], 2) the Global Modeling and Assimilation Office (GMAO/GEOS-3) and the European Centre for Medium-Range Weather Forecasts (ECMWF) near-surface wind fields [packaged with the CERES Single Scanner Footprint (SSF)], 3) the NLDAS NCEP Eta Data Assimilation System (EDAS) forcing (see also Cosgrove et al. 2003), 4) the Variable Infiltration Capacity (VIC) model (Troy et al. 2008) surface temperature, and 5) the MODIS for North American Carbon Program (NACP; Wofsy and Harriss 2002) temporally smoothed and spatially complete leaf area index (F. Gao et al. 2008). All other datasets are briefly summarized herein. Note that NLDAS-VIC $T_{s}$ will be implied when general reference to "NLDAS $T_{s}$ " is made.

\section{a. Remote sensing products}

\section{1) AIRS}

The AIRS on NASA Aqua provides twice-daily global coverage of the atmospheric infrared spectrum (3.7$15.4 \mu \mathrm{m})$ in 2378 channels across three windows: 3.74 $4.61,6.20-8.22$, and $8.8-15.4 \mu \mathrm{m}$. It is accompanied on Aqua by the AMSU, which measures microwave radiances at 15 channels between 23 and $89 \mathrm{GHz}$. Combined measurements from AIRS and AMSU serve as inputs to the AIRS cloud-clearing algorithm (Chahine 1974, 1977; Chahine et al. 2001, 2006) that enables successful soundings $47.5 \%$ and $72.3 \%$ of the time over land and ocean, respectively (Susskind et al. 2003).

AIRS was designed to provide sounding data with vertical resolution and accuracies on par with pointbased radiosonde observations (RAOBs; 1-K RMS error in 1-km tropospheric layers and 20\% RMS error in 2-km tropospheric layers for water vapor), but available globally, for the purpose of improved weather prediction through data assimilation (Susskind et al. 2006). Primary retrievals include atmospheric temperature and humidity profiles, ozone profiles, sea/land surface skin temperature, and cloud properties, including outgoing longwave radiation (Aumann et al. 2003). The observed RMS error can be described as the sum of four terms: 1) instrument noise and forward retrieval model error under perfectly cloud-free and uniform scene conditions, 2) errors introduced by the cloud-clearing algorithm, 3) errors in surface emissivity, and 4) temporal and spatial collocation errors (Chahine et al. 2006).

Since the launch of AIRS in May 2002, significant improvements (version updates) have been made to the original AIRS retrieval algorithm (Susskind et al. 1998) - these are well documented in Susskind et al. (2003) and Susskind et al. (2006). The current state of the AIRS retrieval algorithm, version 5, implements a radiative transfer algorithm (RTA) that accounts for nonlocal thermodynamic equilibrium (NLTE) effects on the shortwave channels, incorporates a new, accurate 
TABLE 1. Data products used in this study: their source, spatial and temporal resolution, and coverage.

\begin{tabular}{|c|c|c|c|}
\hline Variable field(s) & Source (product) & Resolution & Coverage \\
\hline \multicolumn{4}{|l|}{ Satellite remote sensing } \\
\hline $\begin{array}{l}\text { Skin temperature, 2-m air temperature, } \\
\text { specific and relative humidity }\end{array}$ & AIRS V5, V5.2 (AIRX2SUP) & $45 \mathrm{~km} /$ instantaneous & Global \\
\hline Skin temperature & MSG-SEVERI (SAF-LST) & $5 \mathrm{~km} / 15 \mathrm{~min}$ & MSG disc \\
\hline Downward shortwave radiation & $\begin{array}{l}\text { CERES Ed. 2B, 2C } \\
\quad(\text { SSF-46,47) }\end{array}$ & $20 \mathrm{~km} /$ instantaneous & Global \\
\hline UMD land cover classificiation & MODIS V4 (MOD12Q1) & $1 \mathrm{~km} /$ yearly & Global \\
\hline MODIS for NACP leaf area index & MODIS V5 (MOD15A2GFS) & $500 \mathrm{~m} / 8$-daily & North America \\
\hline Snow coverage & $\begin{array}{l}\text { MODIS V5 (MOD10C1, } \\
\text { MYD10C1) }\end{array}$ & $0.05^{\circ}$ daily & Global \\
\hline Topography & SRTM V4 & $90 \mathrm{~m} / \mathrm{static}$ & $60^{\circ} \mathrm{N}-60^{\circ} \mathrm{S}$ \\
\hline \multicolumn{4}{|l|}{ Ground meteorological observations } \\
\hline $\begin{array}{l}\text { 2-m air temperature, } 2-\mathrm{m} \text { dewpoint } \\
\text { temperature, } 2-\mathrm{m} \text { relative humidity, } \\
\text { 10-m wind speed, surface pressure }\end{array}$ & $\begin{array}{l}\text { NCDC ISD (Africa), QCLCD } \\
\quad \text { (CONUS) }\end{array}$ & point/hourly & $\begin{array}{l}\text { CONUS ( } \sim 1500 \text { stations }) \\
\text { and Africa }(\sim 550 \text { stations })\end{array}$ \\
\hline \multicolumn{4}{|l|}{ Model forcing/output } \\
\hline $\begin{array}{l}\text { 2-m temperature, } 2-\mathrm{m} \text { specific humidity, } \\
\text { 10-m U wind component, } 10-\mathrm{m} \mathrm{V} \\
\text { wind component, surface pressure }\end{array}$ & $\begin{array}{l}\text { NLDAS (EDAS/Eta-based } \\
\text { real-time forcing dataset) }\end{array}$ & $0.125^{\circ} /$ hourly & NLDAS domain \\
\hline Surface temperature & VIC-NLDAS & $0.125^{\circ} /$ hourly & CONUS \\
\hline $\begin{array}{l}\text { 10-m U wind component, } 10-\mathrm{m} \mathrm{V} \text { wind } \\
\text { component }\end{array}$ & DAO (GEOS-3) or ECMWF & $20 \mathrm{~km} / 3$ - or 6-hourly & Global \\
\hline Surface pressure & NCEP-GFS & T254/6-hourly & Global \\
\hline Topography & GTOPO30 & $30^{\prime \prime} /$ static & Global \\
\hline
\end{tabular}

cloud clearing algorithm using AIRS spectra only, and provides for the first time, case-by-case product error estimates (Susskind et al. 2010).

\section{(i) Preprocessing}

Here, we use AIRS $T_{s}$ (TSurfStd), $T_{a}$ (TSurfAir), total column precipitable water vapor (pwv; totH2OStd), and near-surface atmospheric temperature (TAirSup) and moisture (H2OCDSup) profiles obtained from the 100-layer AIRX2SUP version 5 (from 1 September 2002 to 30 September 2006) and version 5.2 (from 1 October 2007 to 31 December 2008). We calculate RH (\%) and $q$ $\left(\mathrm{kg} \mathrm{kg}^{-1}\right)$ by first solving for the thickness, $\Delta z(\mathrm{~m})$, of the near-surface atmospheric layer using the hydrostatic approximation and ideal gas law:

$$
\Delta z=\frac{R \bar{T}_{a-1}}{g} \log \left(\frac{P_{\text {surf }}}{P_{1}}\right)
$$

where $R$ is the specific gas constant for dry air (287.05 $\left.\mathrm{J} \mathrm{kg}^{-1} \mathrm{~K}^{-1}\right), \bar{T}_{a-1}$ is the mean layer temperature (K) interpolated from the surface $\left(T_{a}\right)$ and bounding top $\left(T_{1}\right)$ AIRS level temperatures as a linear function of the logarithm of AIRS (NCEP-GFS) pressure (pressSupp), $g$ is the gravitational acceleration $\left(9.807 \mathrm{~m} \mathrm{~s}^{-2}\right)$, and $P_{\text {surf }}$ $(\mathrm{hPa})$ and $P_{1}(\mathrm{hPa})$ are the surface and bounding top AIRS pressure levels, respectively. Next, the water vapor in the layer, $\mathrm{pwv}_{\text {surf- } 1}\left(\mathrm{~kg} \mathrm{~m}^{-2}\right.$ or $\left.\mathrm{mm}\right)$ is calculated by

$$
\operatorname{pwv}_{\text {surf-1 }}=10\left(\mathrm{H}_{2} \mathrm{OCDSup}_{\text {surf }-1}\right) \frac{M}{N_{A}}
$$

where $M$ is the molecular mass of water $\left(18.016 \mathrm{~g} \mathrm{~mol}^{-1}\right)$, $N_{A}$ is the Avogadro constant $\left(6.0221367 \times 10^{23}\right.$ molecules $\mathrm{mol}^{-1}$ ), and H2OCDSup $\mathrm{Hurf}_{-1}$ is the layer amount of water vapor in molecules per centimeters squared, which is interpolated from the bounding bottom (H2OCDSup $_{0}$ ) and top (H2OCDSup 1 ) AIRS layer water vapor amounts, using linear interpolation with logarithmic pressure (Olsen 2007). Then, the vapor pressure, $e(\mathrm{~Pa})$, and saturation vapor pressure, $e_{s}(\mathrm{~Pa})$ are computed by Eqs. (5) and (6), respectively:

$$
\begin{aligned}
e & =R_{v} \bar{T}_{a-1}\left(\frac{\mathrm{pwv}_{\text {surf }-1}}{\Delta z}\right), \\
e_{s} & =611 \exp \left(17.27 \frac{\bar{T}_{a-1}-273.15}{\bar{T}_{a-1}-35.85}\right),
\end{aligned}
$$

where $R_{v}$ is the gas constant for water vapor (461.0 $\mathrm{J} \mathrm{kg}^{-1} \mathrm{~K}^{-1}$ ). Finally, $q$ and $\mathrm{RH}$ are solved via Eqs. (7) and (8), respectively:

$$
\begin{aligned}
q & =0.622 \frac{e}{100 P_{\text {surf }}}, \\
\mathrm{RH} & =100 \frac{e}{e_{s}} .
\end{aligned}
$$


AIRS footprint values of $13.5 \mathrm{~km}$ (at nadir) resolution are quality screened and then spatially interpolated to a $0.125^{\circ}$ geographic coordinate system using an inversedistance-squared interpolation scheme with a great-circle search radius of $75 \mathrm{~km}$. In the case of $T_{a}$ and $T_{s}$, qualityscreened footprint values are first elevation corrected from the AIRS topography (topog) to sea level, then interpolated to grids, and finally, elevation corrected to match the NLDAS $0.125^{\circ}$ elevation using a mean environmental lapse rate (ELR) of $-6.5^{\circ} \mathrm{C} \mathrm{km}^{-1}$, consistent with that applied by NLDAS (Cosgrove et al. 2003) and the Project for Intercomparison of Land surface Parameterizations (PILPS; Bowling et al. 2003). Errors do depend on pressure (elevation) differences (see Fig. A1) and it is feasible to compute an ELR on-the-fly with AIRS (see supplemental Table S1 in the online supplement: http://dx.doi.org/10.1175/2010JHM1217.s1), however at CONUS scale, errors were not found to be sensitive to the precise ELR applied (see supplemental Fig. S1). Whereas $T_{s}$ and $T_{a}$ are level quantities, $q$ and $\mathrm{RH}$ are layer averages, valid for the lowest atmospheric layer (bounded on the bottom by the surface), and therefore were not corrected for elevation. Since the manner in which AIRS quality flags are applied at the footprint scale does substantially affect the sampling and thus the retrieval accuracy characteristics of the gridded product, we provide a summary of our protocol in the appendix.

\section{(ii) Near-surface air temperature and humidity}

Previously, AIRS $T_{a}$ and $q$ have been evaluated as part of the total vertical profile. Divakarla et al. (2006) compared AIRS temperature and water vapor profiles against collocated RAOBs at 538 stations globally for a 2-yr period (September 2002-December 2004) amounting to more than 82000 intercomparisons. Over midlatitude land $\left(50^{\circ}-23^{\circ} \mathrm{N}, 50^{\circ}-23^{\circ} \mathrm{S}\right)$, RMS differences of $T_{a}$ and $q$ ranged from $1.75(P=1000 \mathrm{hPa})$ to $1.25^{\circ} \mathrm{C}$ $(P=800 \mathrm{hPa})$ and $22(P=1000 \mathrm{hPa})$ to $27 \%(P=$ $800 \mathrm{hPa}$ ), respectively (Divakarla et al. 2006). Tobin et al. (2006), through a collaborative effort between the NASA-EOS project and the Department of Energy Atmospheric Radiation Measurement (ARM) program, performed a more targeted intercomparison over multiyear periods at three ARM sites using Aqua overpassdedicated RAOBs. At the ARM Southern Great Plains (SGP) facility, they reported mean RMS differences of approximately $2^{\circ} \mathrm{C}$ and $25 \%$ for $T_{a}$ and $q$, respectively (Tobin et al. 2006). Other studies have intercompared AIRS profiles with forecast models, such as the NCEPGFS and ECMWF (Divakarla et al. 2006; Susskind et al. 2006).
The most thorough regional assessment of AIRS $T_{a}$ to date, to our knowledge, was completed by W. H. Gao et al. (2008) using collocated observations from 540 meteorological stations in China $\left(15^{\circ}-55^{\circ} \mathrm{N}, 75^{\circ}-130^{\circ} \mathrm{E}\right)$ for 2 months (July 2004 and January 2005). Using data of nominal quality (Qual_Temp_Profile_Bot $<2$ ), mean RMS differences for daytime retrievals in July and January were found to be $3.4^{\circ}$ and $2.8^{\circ} \mathrm{C}$, respectively.

Beyond these studies, the best approximation of AIRS accuracies may well be error estimates for the Television and Infrared Observation Satellite (TIROS) Operational Vertical Sounder (TOVS), a first generation AIRS if you will. For example, Lakshmi et al. (2001) showed TOVS afternoon $T_{a}$ retrievals were biased by $+2.1^{\circ} \mathrm{C}$ with RMS differences of $3.8^{\circ} \mathrm{C}$ relative to 26 stations distributed over the Arkansas-Red River basin.

\section{(iii) Surface temperature}

Owing to subfootprint-scale spatial heterogeneity in surface emissivity, $T_{s}$ products remain the most challenging (along with SM) to validate. Thermal infrared (TIR)-based RS sources including: MODIS, the Advanced Very High Resolution Radiometer (AVHRR), Geostationary Operational Environmental Satellites (GOES), geostationary Meteosat satellites, and the Advanced Spaceborne Thermal Emission and Reflection Radiometer (ASTER), offer at a minimum, the opportunity for independent quality checks of $T_{s}$. Knuteson et al. (2008) performed a global intercomparison between average monthly AIRS level 3 version $5 T_{s}$ and upscaled MODIS level 3 (MYD11C3) collection $4 T_{s}$ for July 2003. Across all land cover classes, excluding cases of snow/ice cover, AIRS and MODIS $T_{s}$ agreed within $0.5^{\circ}$ and $1.5^{\circ} \mathrm{C}$ for the night and daytime overpasses, respectively. The AIRS Science Team's current estimate of AIRS $T_{s}$ accuracy is $2^{\circ}-3^{\circ} \mathrm{C}$, globally.

\section{(iv) Total column precipitable water vapor}

We use AIRS pwv to evaluate the impact of water vapor on retrieval performance. Raja et al. (2008) showed strong agreement $(0.91 \leq R \leq 0.98)$ between AIRS and Global Positioning System (GPS) pwv, using more than 375 National Oceanic and Atmospheric Administration (NOAA) Earth System Research Laboratory (ESRL; see online at http://gpsmet.noaa.gov) stations over CONUS, for the period of April-October 2004. The monthly mean bias (AIRS minus GPS) and RMS differences exhibited a systematic seasonal trend, ranging from $-1.2 \mathrm{~mm}$ (July) to $+0.75 \mathrm{~mm}$ (April), and $4.5 \mathrm{~mm}$ (July) to $3.0 \mathrm{~mm}$ (April), respectively (Raja et al. 2008).

A special issue of the Journal of Geophysical Research (2006, Vol. 111) details many of the AIRS Science Team's validation activities (see Fetzer 2006). 


\section{2) SEVIRI/METEOSAT}

The European Organisation for the Exploitation of Meteorological Satellites (EUMETSAT) Land Surface Analysis-Satellite Applications Facility (LSA-SAF) generates, on an operational basis, $T_{s}$ from the SEVIRI/ Meteosat. SEVIRI $T_{s}$ is available for a period of more than $4 \mathrm{yr}$ (July 2005 to the present) at the full SEVIRI temporal ( $\sim 15 \mathrm{~min})$ and spatial $(\sim 3 \mathrm{~km})$ resolution and quality screened for satellite zenith view angle (SZA) $>60^{\circ}$ and cloud cover. The retrieval algorithm is based on the generalized split-window (GSW) algorithm of Wan and Dozier (1996), initially developed for AVHRR and MODIS, but adapted for SEVIRI's 10.8 and $12.0 \mu \mathrm{m}$ channels (Madeira 2002). The algorithm's parameters are functions of the SZA and pwv (obtained from ECMWF forecasts). The channel surface emissivity is computed as the area-weighted mean of bare soil and vegetation emissivities, where the fractional vegetation cover is a SAF-retrieved product (Garcia-Haro et al. 2005) and emissivities are preassigned by class in a land cover map (Peres and DaCamara 2005; Trigo et al. 2008a). The complete methodology is provided in the SAF Land Surface Temperature (LST) Product User Manual (available online at http://landsaf.meteo.pt/).

Errors in SEVIRI $T_{s}$ are known to derive from uncertainties in surface emissivity, topographic complexity (vc), pwv, and SZA (Freitas et al. 2010; Trigo et al. 2008b). Theoretically, given an uncertainty of $1 \%$ in SAF emissivity, SEVIRI $T_{s}$ accuracies should fall within a range of $\pm 2^{\circ} \mathrm{C}$ (Kabsch et al. 2008; Trigo et al. 2008a). The most pronounced errors occur due to the presence of undetected clouds (NWC-SAF 2010). Using matchups at two independent ground radiometers located at the SAF validation station in Mitra, Portugal $\left(38.54^{\circ} \mathrm{N}, 8.00^{\circ} \mathrm{W}\right)$ for 61 and 35 days in 2006, Kabsch et al. (2008) found SEVIRI $T_{s}$ to be systematically biased high $\left(+2.5^{\circ} \mathrm{C}\right)$ at the approximate time of Aqua's daytime overpass.

From its native resolution, SEVIRI $T_{s}$ was first elevation corrected to sea level and then resampled to $0.125^{\circ}$ geographic coordinates using box averaging. Next, the $0.125^{\circ}$ values were elevation corrected to GTOPO30 (see below) mean elevation. Finally, the $0.125^{\circ}$ SEVIRI $T_{s}$ record was queried using a temporal window of $\pm 59 \mathrm{~min}$, or in other words \pm 3 SEVIRI time steps, to determine the nearest temporal match to the coincident AIRS retrieval. The current LSA-SAF $T_{s}$ retrieval algorithm (version 7.2) has benefited from a series of modifications over the period of record (Trigo et al. 2008b). Unfortunately, a complete reprocessing of the time series has not occurred. Therefore, we use the discontinuous SEVIRI $T_{s}$ record as is. Beginning on 8 July 2008 , the LSA-SAF $T_{s}$ product provides greater spatial coverage and case-by-case error estimates. We sample this later period using the legacy LSA-SAF "nominal" and "below nominal" accuracy levels, or RMS $<2^{\circ} \mathrm{C}$, and RMS $>2{ }^{\circ} \mathrm{C}$, to match the spatial coverage of the earlier record.

\section{3) CERES}

The hourly CERES Aqua SSF top-of-atmosphere (TOA)/Surface Fluxes and Clouds product contains highaccuracy instantaneous surface and TOA radiation budget datasets from measurements taken by CERES broadband radiometers and a 19-channel subset of the 36-channel MODIS (also onboard Aqua). We use the downward shortwave (SW $\downarrow$ ) model B estimates, calculated by the Langley Parameterized SW Algorithm (LPSA; Darnell et al. 1992; Gupta et al. 2001) to produce $0.20^{\circ}$ daily global maps of $\alpha_{\text {cloud }}$. We first apply an inversedistance-weighting scheme with a search radius of $0.80^{\circ}$ to interpolate SSF footprint values (20 km at nadir) to $0.20^{\circ}$ geographic coordinates. Then, we calculate $\alpha_{\text {cloud }}$ by the following relation:

$$
\alpha_{\text {cloud }}=1-\frac{\mathrm{SW}_{i}}{\mathrm{SW}_{\text {clear }}},
$$

where $\mathrm{SW}_{i}$ is the time-of-overpass $\mathrm{SW} \downarrow$, and $\mathrm{SW}_{\text {clear }}$ is the maximum $\mathrm{SW} \downarrow$ over an 8 -day, $1^{\circ} \times 1^{\circ}$ spatial window centered on the pixel of interest. By calculating $\alpha_{\text {cloud }}$ in this way, we inherently correct for local atmospheric effects, including dust and smoke. The most current edition, edition 2C, was available only for January and May 2006, and December 2006-August 2007. For all other months, edition $2 \mathrm{~B}$ was used. Edition $2 \mathrm{~B}$ and $2 \mathrm{C}$ differ only by the collection version of MODIS input, with the later using collection 5 and the prior using collection 4.

AIRX2SUP (see above) does include a TIR cloud fraction (TotCld_4_CCfinal) estimate valid for the AIRS field of regard $(45 \mathrm{~km})$ that generally agrees well with $\alpha_{\text {cloud }}$ (CONUS: $\tau=0.41$ ). However, we found that $\alpha_{\text {cloud }}$ was a stronger explanatory variable of accuracy (see supplemental Figs. S4-S5) over arid regions.

\section{4) MODIS LAND COVER CLASSIFICATION}

The MODIS Terra collection 4, 1-km yearly lc classification product (MOD12Q1; Friedl 1996) 14-class University of Maryland (UMD) scheme (Hansen et al. 2000) was used. Data tiles were first mosaiced and then reprojected from their native sinusoidal projection to $0.01^{\circ}$ geographic coordinates using the MODIS Reprojection Tool (MRT) version 4.0. Since, at the time of writing, MOD12Q1 was only available for years 2001-04, year 2004 was used. 
TABLE 2. The number of NCDC ground meteorological stations included in the analyses, listed by variable and domain. The percent of culled stations is denoted in parentheses.

\begin{tabular}{lccccc}
\hline \hline \multicolumn{1}{c}{ Subdomain } & Surface pressure & Relative humidity & Specific humidity & Air temperature & $10 \mathrm{~m}$ wind \\
\hline CONUS (NLDAS vs NCDC) & $1480(0.6 \%)$ & $1491(0.1 \%)$ & $1489(0 \%)$ & $1490(0 \%)$ & $1488(0.3 \%)$ \\
CONUS (AIRS vs NCDC) & $1467(1.5 \%)$ & $1489(0.3 \%)$ & $1490(0 \%)$ & $1491(0 \%)$ & $1379(4.0 \%)$ \\
Africa (AIRS vs NCDC) & $420(2.8 \%)$ & $554(2.1 \%)$ & $424(1.4 \%)$ & $561(0.4 \%)$ & $443(17.4 \%)$ \\
\hline
\end{tabular}

\section{5) GTOPO30}

The GTOPO30 global 30 arc second $(\sim 1 \mathrm{~km})$ digital elevation model (DEM) was first resampled to $0.125^{\circ}$ geographic coordinates using box averaging and then applied to elevation correct the AIRS and SEVIRI temperature products (see above). This ensures topographic consistency, since NLDAS (and NLDAS-VIC) data are also GTOPO30 based.

\section{6) SRTM-90M}

The void-filled Shuttle Radar Topography Mission (SRTM) version 4, 90-m DEM (Reuter et al. 2007) was used to generate $0.125^{\circ}$ fields of vc, defined as the standard deviation of SRTM 90-m elevation.

\section{7) MODIS SNOW COVER}

We use the MODIS Terra (MOD10C1) and MODIS Aqua (MYD10C1; Hall et al. 2002) collection $50.05^{\circ}$ daily global $S C A$ products. These products were created using the daily MODIS Terra and MODIS Aqua 500-m tile products, MOD10A1 and MYD10A1, respectively. MYD10C1 is currently considered "provisional," while MOD10C1 has been well validated (Hall and Riggs 2007).

\section{b. In situ data}

For the total record, hourly observations of $10-\mathrm{m}$ wind (w), $T_{a}, 2-\mathrm{m}$ dewpoint temperature $\left(T_{d}\right)$, and surface pressure $\left(P_{\text {surf }}\right)$ or alternatively, altimeter setting (alt), were obtained from the NCDC ISD. The ISD comprises worldwide surface weather observations from approximately 20000 stations historically $(\sim 12000$ available for 1995-2007), collected and stored from sources such as: the Automated Weather Network (AWN), the Global Telecommunications System (GTS), the Automated Surface Observing System (ASOS), as well as data keyed from paper forms (Lott et al. 2001). ISD data have undergone extensive automated quality control (Lott, 2004). Over CONUS, NCDC maintains an additional, more extensively screened database called the Quality Controlled Local Climatological Database (QCLCD).

For this study, data for Africa were obtained from ISD (available 27 January 2009: available online at ftp:// ftp.ncdc.noaa.gov/pub/data/noaa/); data for CONUS were obtained from QCLCD v1.4 (available 28 January 2009: available online at http://cdo.ncdc.noaa.gov/qclcd_ascii/). Only observations satisfying the strictest quality flags were accepted. Furthermore, only stations with more than 50 matched (within $\pm 90 \mathrm{~min}$ of the overpass) observations were considered. The median sample size per station over CONUS and Africa was $1695 \pm 642$ and $642 \pm 462$, respectively. Stations that satisfied the initial sample size criterion were then screened once more on a per variable basis using the Kendall's $\tau$ correlation metric (hereafter $\tau$ ). Any station/variable for which AIRS (NLDAS)NCDC time series failed to correlate at the $p=0.01$ significance level were culled from the analyses (see Table 2). Over CONUS and Africa, approximately 1500 and 500 stations were included, respectively (see Table 2).

For many stations in Africa, pressure is reported in the form of an altimeter setting. In these cases, $P_{\text {surf }}$, is calculated following Eqs. (10)-(12):

$$
\begin{aligned}
P_{\text {surf }} & =\left(\text { alt }^{n}-B h \times 10^{-8}\right)^{1 / n}+0.3, \\
B & =\frac{R T_{a}}{g}, \\
n & =\frac{R \times \text { ELR }}{g},
\end{aligned}
$$

where $P_{\text {surf }}$ is in units of hPa, $h$ is the station elevation in meters (m), alt is in $\mathrm{hPa}$, and $T_{a}$ is in $\mathrm{K}$. When $\mathrm{RH}$ is not provided, it is computed from the dewpoint temperature, $T_{d}$, and $T_{a}$ through an approximation of the ClausiusClapeyron equation:

$$
\mathrm{RH}=100 \exp \left\{17.27\left[\left(\frac{T_{d}}{237.3+T_{d}}\right)-\left(\frac{T_{a}}{237.3+T_{a}}\right)\right]\right\}
$$

where RH is in percent, $T_{d}$ is in ${ }^{\circ} \mathrm{C}$, and $T_{\mathrm{a}}$ is also in ${ }^{\circ} \mathrm{C}$. Specific humidity, $q\left(\mathrm{~kg} \mathrm{~kg}^{-1}\right)$, is not available directly from observations and is calculated from Eq. (7), where $e$ is the partial pressure of water vapor in $\mathrm{Pa}$ as given by Eq. (14): 
TABLE 3. Overview of the break points utilized in the conditional sampling analyses over CONUS (section 4a) and Africa (section 4b). (from top to bottom) Roughly correspond with the box plots (from left to right) in Figs. 7 and 11. The break points for cloud albedo were identical for both domains.

\begin{tabular}{|c|c|c|c|c|c|c|c|c|c|}
\hline \multirow[b]{2}{*}{$\begin{array}{l}\text { Clouds } \\
\left(\alpha_{\text {cloud }}\right)\end{array}$} & \multicolumn{5}{|c|}{ CONUS } & \multicolumn{4}{|c|}{ Africa } \\
\hline & $\begin{array}{c}\text { AIRS surface } \\
\left(T_{s}\right) \text { or air } \\
\left(T_{a}\right) \text { temperature } \\
\left({ }^{\circ} \mathrm{C}\right)\end{array}$ & $\begin{array}{c}\text { Total column } \\
\text { precipitable water } \\
\text { vapor/ice (pwv) } \\
(\mathrm{mm})\end{array}$ & $\begin{array}{l}\text { Elevation } \\
\quad(\mathrm{m})\end{array}$ & $\begin{array}{l}\text { Vertical } \\
\text { complexity } \\
(\mathrm{vc})(\mathrm{m})\end{array}$ & $\begin{array}{l}\text { Leaf area } \\
\text { index } \\
(\mathrm{LAI})\end{array}$ & $\begin{array}{c}\text { Total column } \\
\text { precipitable water } \\
\text { vapor/ice } \\
(\mathrm{pwv})(\mathrm{mm})\end{array}$ & $\begin{array}{l}\text { Elevation } \\
\quad(\mathrm{m})\end{array}$ & $\begin{array}{l}\text { Vertical } \\
\text { complexity } \\
(\mathrm{vc})(\mathrm{m})\end{array}$ & $\begin{array}{l}\text { Leaf area } \\
\text { index } \\
\text { (LAI) }\end{array}$ \\
\hline 0 & $<0$ & 0 & 0 & 0 & 0 & 0 & 0 & 0 & 0 \\
\hline 0.05 & 0 & 3.18 & 236 & 9.6 & 0.43 & 6.34 & 284 & 7.2 & 0.33 \\
\hline 0.2 & 20 & 6.00 & 418 & 17.9 & 0.79 & 11.37 & 436 & 14.4 & 0.60 \\
\hline 0.4 & 30 & 9.92 & 740 & 36.4 & 1.22 & 17.49 & 640 & 25.6 & 0.95 \\
\hline \multirow[t]{3}{*}{0.6} & & 14.37 & 1622 & 108.1 & 2.01 & 25.20 & 1063 & 58.6 & 1.74 \\
\hline & & 21.04 & & & & 35.41 & & & \\
\hline & & 34.29 & & & & 46.35 & & & \\
\hline
\end{tabular}

$$
e=611 \exp \left[17.27\left(\frac{T_{d}}{237.3+T_{d}}\right)\right]
$$

\section{c. Methods}

For all comparisons, we compute three sample statistics: bias, unbiased RMS (ubRMS, a.k.a. the random error), and Kendall's $\tau$ nonparametric correlation. Bias is calculated by

$$
\text { bias }=\frac{1}{n} \sum_{i=1}^{n}\left(\mathrm{AIRS}_{i}-\text { meas }_{i}\right)
$$

where meas $_{i}$ is the in situ, or otherwise "true" measurement. The ubRMS is calculated by

$$
\text { ubRMS }=\sqrt{\mathrm{RMS}^{2}-\text { bias }^{2}},
$$

where

$$
\mathrm{RMS}=\sqrt{\frac{1}{n-1} \sum_{i=1}^{n}\left(\mathrm{AIRS}_{i}-\text { meas }_{i}\right)^{2}},
$$

and $n$ represents the sample size. In the case of $q$ and $\mathrm{RH}$, relative bias and relative ubRMS (ubRMSP) are used instead:

$$
\begin{aligned}
\text { relative bias } & =\frac{\text { bias }}{\overline{\text { meas }}} \times 100, \\
\text { ubRMSP } & =\frac{\text { ubRMS }}{\overline{\text { meas }}} \times 100,
\end{aligned}
$$

where $\overline{\text { meas }}$ is the time series mean of the measured quantity (i.e., NLDAS $q$ or NLDAS RH). This approach provides easily interpreted/applied values that are minimally influenced by errors during dry extremes, but still normalized by the annual mean climatology. Differentiation between bias and random error becomes less meaningful as the correlation, or confidence in the bias correction, diminishes. Reference to the "agreement" of two datasets shall imply the Kendall's $\tau$ correlation. Likewise, reference to "uncertainty" or "accuracy" shall imply the ubRMS (or ubRMSP).

\section{Results}

Over CONUS we first evaluate the AIRS and NLDAS data against NCDC in situ observations [section 4a(1)] and then evaluate AIRS relative to NLDAS offline data [section $4 \mathrm{a}(2)$ ]. Spatially and temporally continuous (hourly) fields of elevation-corrected and validated (Luo et al. 2003; Mitchell et al. 2004) NLDAS meteorology afford the maximum number of matchups with AIRS. We exploit these data characteristics to evaluate the skill of AIRS retrievals over a broad range of surface and atmospheric conditions [section $4 \mathrm{a}(2)$ ]. Specifically, we take sample subsets along gradients (generally quintiles) of AIRS $T_{s}$ or $T_{a}, \alpha_{\text {cloud, }}$, pwv, elevation, vc, UMD lc class, LAI, and season, including SCA. The precise break points that we employed are provided in Table 3, listed by domain. Quintiles were used for the pwv (calculated from the January through December 2004 distribution), elevation, vc, and LAI. In the case of pwv, two supplemental levels - the 5th and 95th percentile-were also included. The break points for $\alpha_{\text {cloud }}$ and $T_{s}$ or $T_{a}$ were selected arbitrarily. The warm and cold seasons correspond to the months of May-September and October-April, respectively. Similar analyses were carried out over Africa between AIRS and NCDC [section 4b(1)] and AIRS and SEVIRI [section $4 \mathrm{~b}(2)$ ]. Quoted statistics are for the total record, unless otherwise noted.

\section{a. Continental United States}

\section{1) COMPARISON WITH NCDC}

Figures 1 and 2 illustrate the spatial distribution of AIRS-NCDC (Fig. 1) and NLDAS-NCDC (Fig. 2) 

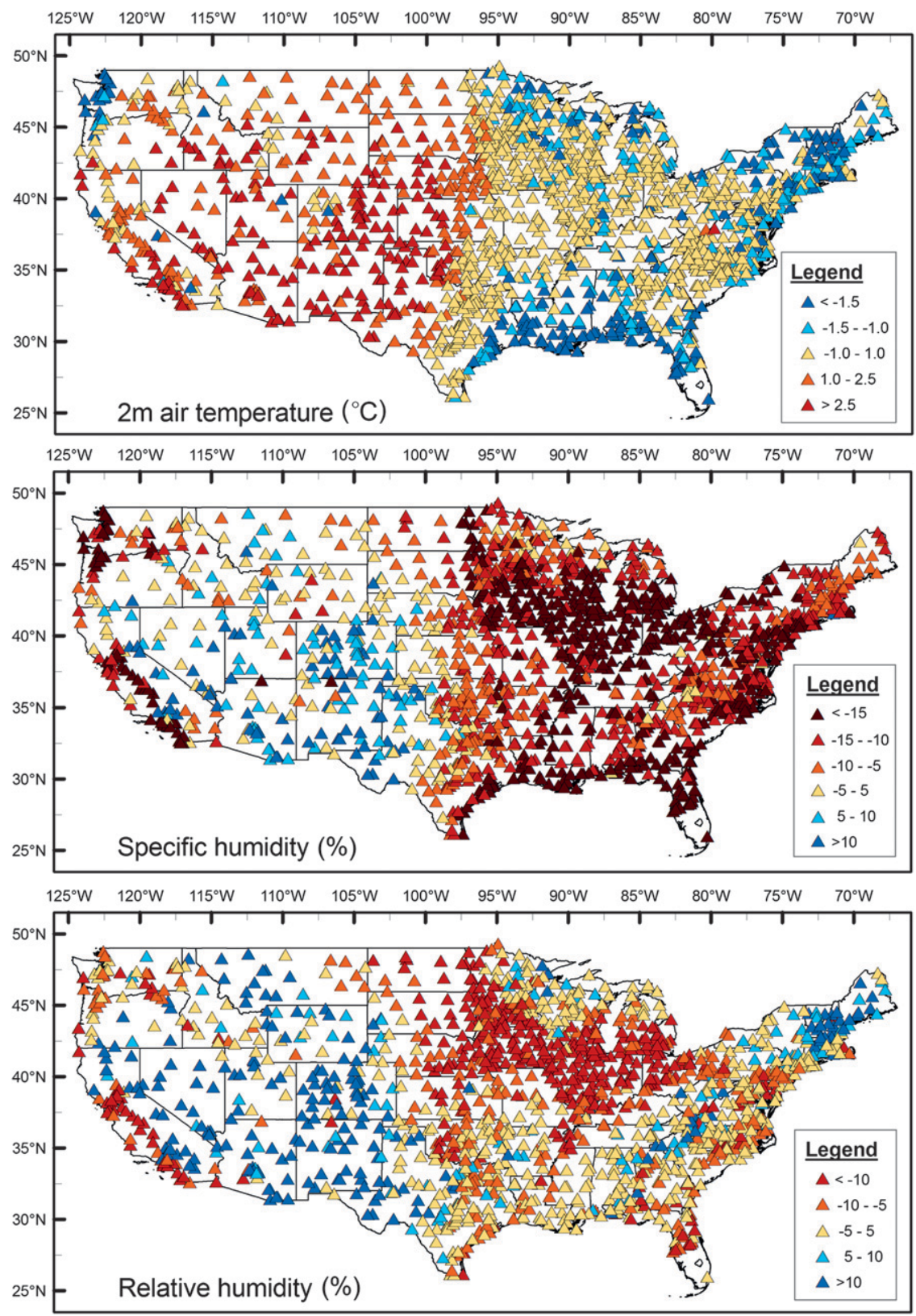

FIG. 1. Mean AIRS-NCDC bias $\left(T_{a}\right)$ and relative bias ( $q$ and $\left.\mathrm{RH}\right)$ computed for the total record.

mean bias $\left(T_{a}\right)$ and relative bias ( $q$ and $\left.\mathrm{RH}\right)$. Figure 3 shows the spatial distribution of correlation between GFS and NCDC $P_{\text {surf }}$ and GEOS- 3 and NCDC $w$. Figure 4 provides side-by-side comparisons of the frequency distributions of error statistics from AIRS/GFS/GEOS-3NCDC and NLDAS-NCDC matchups for all variablesthe mean statistics of which have been summarized in Table 4.

Figure 1 shows a strong east (cold or neutral) to west (warm) transition in AIRS $T_{a}$ bias occurs near $97.5^{\circ} \mathrm{W}$-right along the hot spot region and typical strong vegetation/soil moisture gradient, not mirrored by NLDAS. The $T_{a}$ bias is well correlated with elevation $(\tau=0.49$, Pearson's $R=0.62)$, particularly for mean elevations greater than $500 \mathrm{~m}$, with slope of $+2.1^{\circ} \mathrm{C} \mathrm{km}^{-1}$. For a majority of the Midwest, $T_{a}$ is shown to have an absolute bias of less than $1^{\circ} \mathrm{C}$. Over central Iowa $\left(41^{\circ}-43^{\circ} \mathrm{N}, 94^{\circ}-92^{\circ} \mathrm{W}, n=53\right), T_{a}$ is in fact unbiased $\left(0^{\circ} \mathrm{C}\right.$, $n=16)$. Elsewhere, along the Texas-Oklahoma border $\left(34^{\circ}-37^{\circ} \mathrm{N}, 103^{\circ}-98^{\circ} \mathrm{W}\right)$ the mean bias is $+3.0^{\circ} \mathrm{C}(n=24)$ 

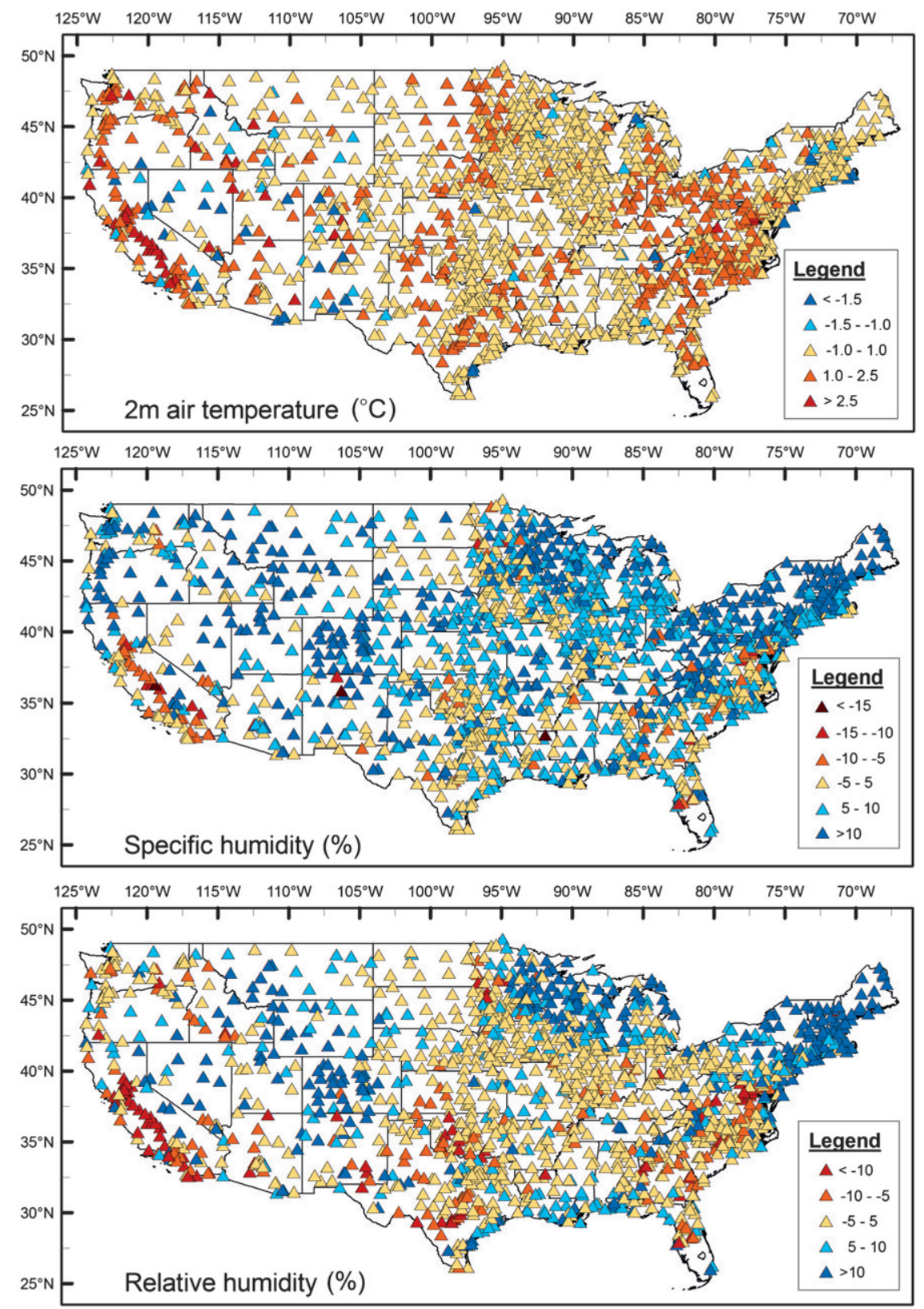

FIG. 2. As in Fig. 1, but for the NLDAS-NCDC intercomparisons.

and along the Gulf Coast $\left(29^{\circ}-31.5^{\circ} \mathrm{N}, 95^{\circ}-85^{\circ} \mathrm{W}\right)$ the mean bias is $-2.1^{\circ} \mathrm{C}(n=53)$.

Figures 1 and 4 show that $q$ is predominantly biased dry (negative). If we consider the same regions (as above), we find $q$ to have a relative bias of $+0.7 \%$ (Texas-Oklahoma), $-17.7 \%$ (Gulf Coast), and $-19.9 \%$ (central Iowa). On the other hand, RH has a slight positive (wet) bias over CONUS. Although, over the same regions, RH has a relative bias of $-2.5 \%$ (TexasOklahoma), $+0.2 \%$ (Gulf Coast), and $-14.2 \%$ (central Iowa). Most of the dry bias in $\mathrm{RH}$ occurs within a distinct band known as the Midwest "corn belt" (see Fig. 1).

As shown in Fig. 4, there is a bimodal distribution of GFS-NCDC (and NLDAS-NCDC) $P_{\text {surf }}$ correlation and random error. We determined that the area east of $97.5^{\circ} \mathrm{W}$ was the source of this pattern. For example, 35 of 69 stations in Illinois have a $\tau$ less than 0.20 and ubRMS greater than $7.5 \mathrm{hPa}$. Of the remaining stations, 32 have a $\tau$ greater than 0.84 and ubRMS less than $2.0 \mathrm{hPa}$. Overall, both GFS and NLDAS $P_{\text {surf }}$ and GEOS- 3 and NLDAS $w$ datasets are most uncertain west of $104^{\circ} \mathrm{W}$ 

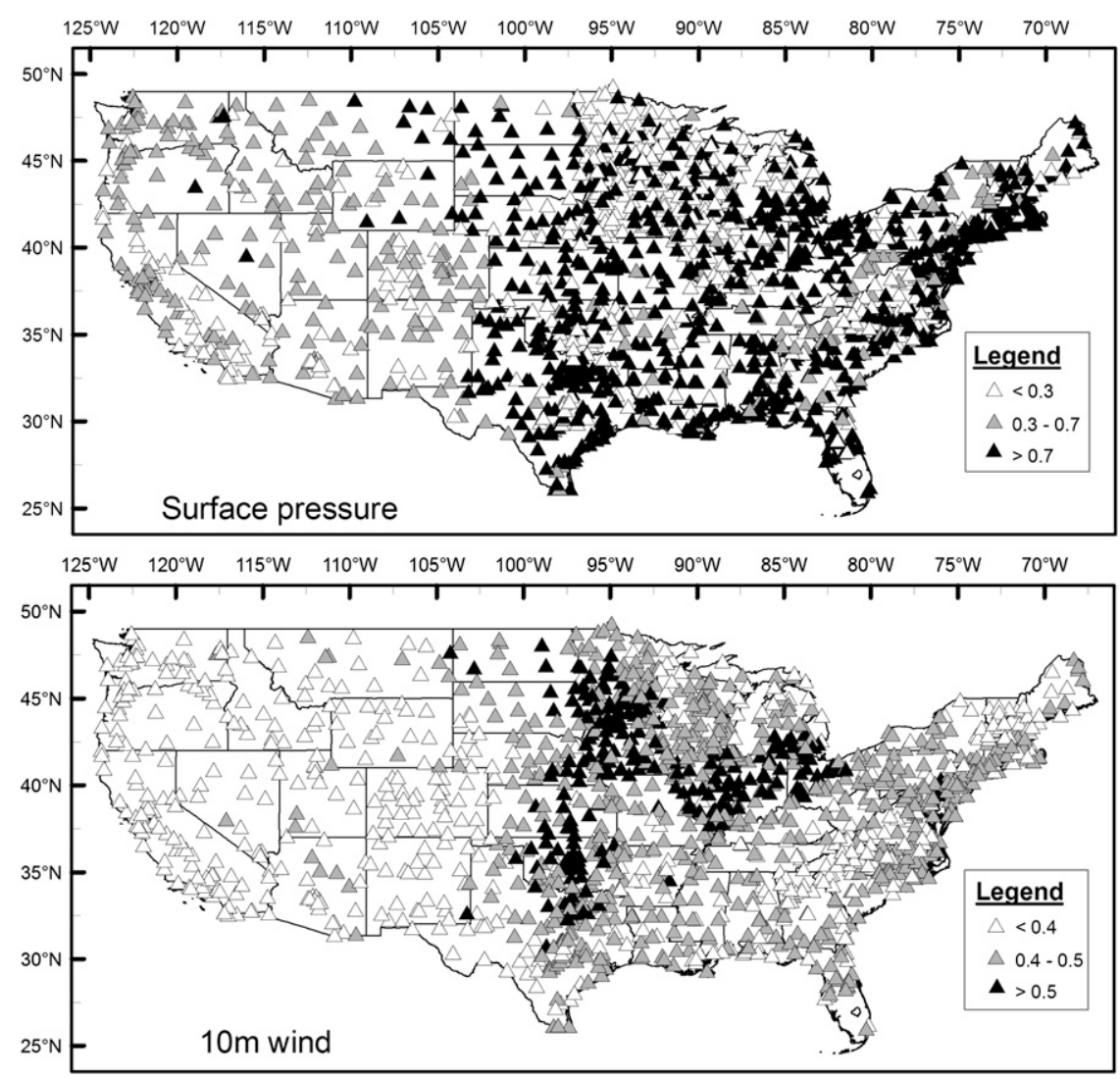

FIG. 3. (top) GFS-NCDC $P_{\text {surf }}(\mathrm{hPa})$ and (bottom) GEOS-3-NCDC $w\left(\mathrm{~m} \mathrm{~s}^{-1}\right)$ Kendall's $\tau$ correlation computed for the total record.

(west). The median RMS error for GFS (NLDAS) $P_{\text {surf }}$ is $21.1 \mathrm{hPa}(10.1 \mathrm{hPa})$ in the west $(n \sim 300)$ and $6.2 \mathrm{hPa}$ $(4.6 \mathrm{hPa})$ in the east $(n \sim 1160)$. The median RMS error for GEOS-3 (NLDAS) $w$ is $2.2 \mathrm{~m} \mathrm{~s}^{-1}\left(2.1 \mathrm{~m} \mathrm{~s}^{-1}\right)$ in the west and $1.7 \mathrm{~m} \mathrm{~s}^{-1}\left(1.8 \mathrm{~m} \mathrm{~s}^{-1}\right)$ in the east. GFS $P_{\text {surf }}$ is distinctly biased low in the West (median $=-17.9 \mathrm{hPa})$, but nearly unbiased in the East $($ median $=+0.4 \mathrm{hPa})$. Area-mean GFS $P_{\text {surf }}$ is biased relatively low in northern New York, New Hampshire, and Vermont $(-10.9$ hPa, $n=39$ ) and high in the Midwest (Minnesota, Wisconsin, Iowa, and Illinois: $+5.0 \pm 6.8 \mathrm{hPa}, n=263)$ and Virginia and North Carolina $(+6.1 \mathrm{hPa}, n=96)$. GEOS-3 $w$ is biased low in Texas, Oklahoma, Kansas, eastern New Mexico, and southern California $\left(-0.73 \pm 0.63 \mathrm{~m} \mathrm{~s}^{-1}\right.$, $n=257)$ and slightly high along the eastern coast (Delaware, Maryland, Virginia, North Carolina, South Carolina, and Georgia: $+0.5 \pm 0.5 \mathrm{~m} \mathrm{~s}^{-1}, n=170$ ). Over CONUS, GFS $P_{\text {surf }}$ and GEOS-3 $w$ have mean biases of $-2.5 \mathrm{hPa}$ and $-0.1 \mathrm{~m} \mathrm{~s}^{-1}$, respectively (Table 4). Agreement between GFS and NCDC $P_{\text {surf }}(\tau=-0.54)$, and to a lesser extent GEOS-3 and NLDAS $w(\tau=$ -0.29 ), was found to be anticorrelated with vc.

Relative to the NCDC stations (truth), NLDAS, and AIRS/GFS/GEOS-3 exhibit different error characteristics
(Fig. 4). For all variables, NLDAS forcing is consistently better correlated with less uncertainty relative to AIRS/ GFS/GEOS-3. Differences between GFS and NLDAS $P_{\text {surf }}$ and GEOS-3 and NLDAS $w$, which are both model outputs, may be attributed to issues of scale (GFS $P_{\text {surf }} \sim$ $45 \mathrm{~km}$, GEOS-3 $w \sim 20 \mathrm{~km}$, and NLDAS $\sim 12.5 \mathrm{~km}$ ).

Relative to NCDC, AIRS, and NLDAS: 1) $T_{a}$ are similarly biased $\left( \pm 0.5^{\circ} \mathrm{C}\right)$ over Iowa, Missouri, southern Wisconsin, and eastern Oklahoma; 2) $q$ are similarly biased $( \pm 5 \%)$ over northern and western Texas and western Oklahoma; and 3) $\mathrm{RH}$ are similarly biased ( $\pm 5 \%$ ) over the larger part of CONUS, but disagree in sign over the Midwest (e.g., Minnesota, Wisconsin, Iowa, northern Illinois, northern Indiana, Ohio), and the Southeast (e.g., Alabama, Georgia, South Carolina, North Carolina, and Virginia). However, the domain-averaged bias of AIRS $(-10.3 \%)$ and NLDAS $(+8.8 \%) q$ are of opposite sign (Table 4). Over California's Sacramento River valley $(n=25)$, both AIRS and NLDAS are shown to be biased warm (AIRS: $+1.6^{\circ} \mathrm{C}$; NLDAS: $+2.3^{\circ} \mathrm{C}$ ) and dry (AIRS $q$ : $-14.5 \%$; NLDAS $q:-6.8 \%$ ).

When NLDAS is used as the surrogate truth (next section) for calculating AIRS bias, the true AIRS bias (i.e., AIRS minus NCDC) may be under (subtractive) or 

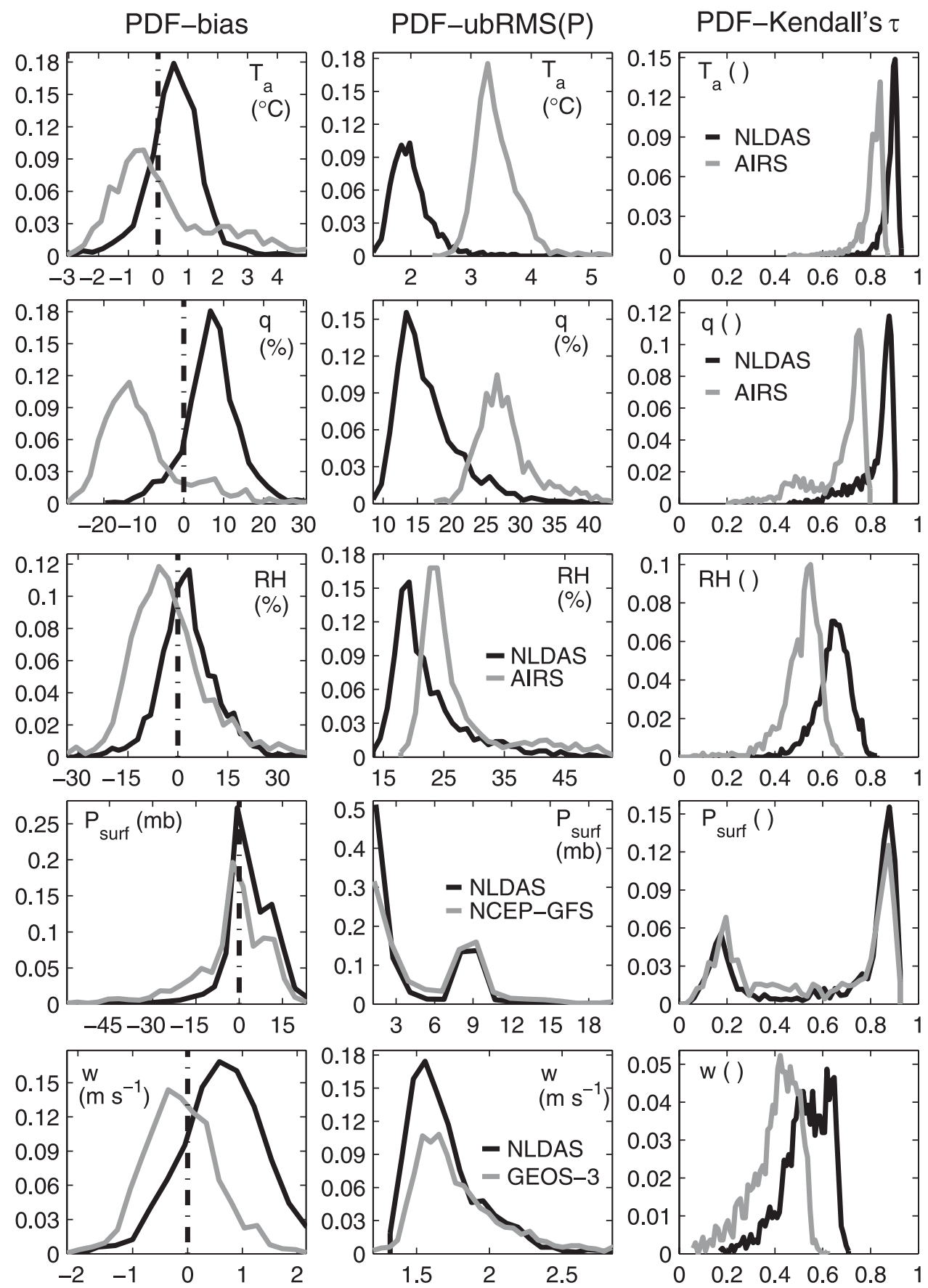

FIG. 4. Frequency distributions of NLDAS-NCDC (black) and AIRS $\left(T_{a}, q\right.$, and RH)/GFS $\left(P_{\text {surf }}\right) /$ GEOS-3 (w)-NCDC (gray) error statistics over CONUS computed for the total record. The bias and ubRMS differences for $q$ and RH are provided in relative terms (ubRMSP), as discussed in section 3. (left and middle) The plotting limits for the bias and random error are the minimum 5th and maximum 95th percentiles of the two samples. The number of contributing stations differs by variable (see Table 2).

over (additive) represented-a function of the inherent NLDAS-NCDC error characteristics. Accordingly, it is feasible that the sign of the true AIRS-NCDC bias differs from the calculated AIRS-NLDAS bias. Such cases are fairly limited, but do occur at $7.1 \%(q), 9.8 \%$ $\left(T_{a}\right)$, and $12.0 \%(\mathrm{RH})$ of the NCDC stations.

The representativeness of the NCDC ground station network at the scale of AIRS, especially in the West, 
TABLE 4. Summary of the mean error statistics for the AIRS $\left(T_{\mathrm{a}}, q\right.$, and RH)/GFS $\left(P_{\text {surf }}\right) /$ GEOS-3 ( $\left.w\right)-$ NLDAS (CONUS and Africa), and NLDAS-NCDC (CONUS) meteorology. Values are calculated using all available stations (see Table 2) for the total record.

\begin{tabular}{|c|c|c|c|}
\hline Comparison pair & Bias (relative bias) & ubRMS (ubRMSP) & Kendall's $\tau$ \\
\hline \multicolumn{4}{|l|}{ Air temperature $\left(T_{a}\right)$} \\
\hline AIRS-NCDC & $+0.2^{\circ} \mathrm{C}$ & $3.4^{\circ} \mathrm{C}$ & 0.80 \\
\hline NLDAS-NCDC & $+0.5^{\circ} \mathrm{C}$ & $2.0^{\circ} \mathrm{C}$ & 0.88 \\
\hline AIRS-NCDC (Africa) & $+1.0^{\circ} \mathrm{C}$ & $3.4^{\circ} \mathrm{C}$ & 0.61 \\
\hline \multicolumn{4}{|l|}{ Specific humidity $(q)$} \\
\hline AIRS-NCDC & $-0.9 \mathrm{~g} \mathrm{~kg}^{-1}(-10.3 \%)$ & $2.3 \mathrm{~g} \mathrm{~kg}^{-1}(28.4 \%)$ & 0.67 \\
\hline NLDAS-NCDC & $+0.5 \mathrm{~g} \mathrm{~kg}^{-1}(+8.8 \%)$ & $1.3 \mathrm{~g} \mathrm{~kg}^{-1}(17.7 \%)$ & 0.82 \\
\hline AIRS-NCDC (Africa) & $-1.4 \mathrm{~g} \mathrm{~kg}^{-1}(-12.4 \%)$ & $3.2 \mathrm{~g} \mathrm{~kg}^{-1}(27.9 \%)$ & 0.45 \\
\hline \multicolumn{4}{|l|}{ Relative humidity (RH) } \\
\hline AIRS-NCDC & $-1.8 \%(-1.4 \%)$ & $13.3 \%(27.9 \%)$ & 0.51 \\
\hline NLDAS-NCDC & $+1.6 \%(+3.4 \%)$ & $11.3 \%(22.6 \%)$ & 0.64 \\
\hline AIRS-NCDC (Africa) & $-5.1 \%(-10.5 \%)$ & $12.2 \%(29.7 \%)$ & 0.48 \\
\hline \multicolumn{4}{|l|}{ Surface pressure $\left(P_{\text {surf }}\right)$} \\
\hline NCEP-GFS-NCDC & $-2.5 \mathrm{mb}$ & $5.7 \mathrm{mb}$ & 0.56 \\
\hline NLDAS-NCDC & $+4.1 \mathrm{mb}$ & $4.7 \mathrm{mb}$ & 0.63 \\
\hline NCEP-GFS-NCDC (Africa) & $-0.9 \mathrm{mb}$ & $4.4 \mathrm{mb}$ & 0.51 \\
\hline \multicolumn{4}{|l|}{$10-\mathrm{m}$ wind $(w)$} \\
\hline DAO (GEOS-3) or ECMWF-NCDC & $-0.1 \mathrm{~m} \mathrm{~s}^{-1}$ & $1.8 \mathrm{~m} \mathrm{~s}^{-1}$ & 0.40 \\
\hline NLDAS-NCDC & $+0.6 \mathrm{~m} \mathrm{~s}^{-1}$ & $1.7 \mathrm{~m} \mathrm{~s}^{-1}$ & 0.53 \\
\hline DAO (GEO-3) or ECMWF-NCDC (Africa) & $+0.1 \mathrm{~m} \mathrm{~s}^{-1}$ & $2.2 \mathrm{~m} \mathrm{~s}^{-1}$ & 0.27 \\
\hline
\end{tabular}

where station density falls off and vc increases, is disputable. Station data is also not without error. Biases are introduced through the affect of localized influences due to imperfect siting (i.e., proximity to trees, buildings, and parking lots; Davey and Pielke 2005). We therefore argue that NLDAS forcing, the accuracy of which we have demonstrated, rather than NCDC stations, is more appropriate for comparisons conducted on the scale order of AIRS. Accordingly, in the conditional sampling analyses to follow, we use NLDAS forcing as surrogate truth.

\section{2) COMPARISON WITH NLDAS}

Figure 5 shows the geographic distribution of AIRS warm season retrieval accuracies relative to NLDAS. Overall, patterns in AIRS-NCDC (Fig. 1) and AIRSNLDAS (Fig. 5) bias are spatially coherent. The median AIRS-NLDAS biases were found to be $+2.1^{\circ} \mathrm{C}\left(T_{s}\right)$, $-0.5^{\circ} \mathrm{C}\left(T_{a}\right),-17.5 \%(q)$, and $-7.0 \%(\mathrm{RH})$. The median random errors are $4.4^{\circ} \mathrm{C}\left(T_{s}\right), 3.2^{\circ} \mathrm{C}\left(T_{a}\right), 20.8 \%(q)$, and $22.3 \%(\mathrm{RH})$. Agreement between AIRS and NLDAS is generally strong with median $\tau \mathrm{s}$ of $0.62\left(T_{s}\right)$, $0.66\left(T_{a}\right), 0.55(q)$, and $0.48(\mathrm{RH})$. For $T_{s}$, the ubRMS local maxima are centered over the Midwest corn belt and the West Texas high plains. For $T_{a}, q$, and $\mathrm{RH}$, the largest uncertainty is observed in the West, but particularly in California and Nevada for $q$ and RH. Local minima in correlation occur over the Southeast ( $T_{s}$ and $T_{a}$ ) and along the Gulf Coast and Pacific Northwest $(q)$.
The patterns of RH error and correlation represent the combined effect of $T_{\mathrm{a}}$ and $q$ accuracy characteristics. Across CONUS, $q$ is biased dry (negative) with the exception of the Cascade, Sierra Nevada, and Peninsular mountain ranges of California, which coincidentally, are also local maxima of uncertainty (ubRMSP $>30 \%$ ). Anomaly correlations computed using a climatological (2002-08) \pm 5 -day moving average of each respective product/variable (AIRS and NLDAS), show that seasonality does impact the error characteristics-much more so for humidity than temperature. [Supplemental Fig. S2 details the seasonal dependence for each of the 13 major river basins in CONUS, as calculated from AIRS footprint (not gridded) retrievals.]

Figure 6 provides maps of AIRS surface air temperature gradient $\left(T_{s}-T_{a}\right)$ error characteristics, also for the warm season. The bias is positive for all pixels, with a median of $+2.1^{\circ} \mathrm{C}$ and 95 th percentile equal to $+6.1^{\circ} \mathrm{C}$. The median $\tau$ and ubRMS differences were $0.2^{\circ}$ and $3.4^{\circ} \mathrm{C}$, respectively. Over the domain, we observed an anticorrelation between bias and LAI $(\tau=-0.46)$ and a positive correlation between elevation and bias $(\tau=0.28)$. Here, LAI is calculated as the 4-yr (2003-06) warm season mean MODIS for NACP product (F. Gao et al. 2008; Jonsson and Eklundh, 2004). The strongest correlation occurs over the Great Plains.

The fact that the AIRS $T_{s}-T_{a}$ gradient has a strong (positive) bias relative to NLDAS, particularly over the West, suggests that NLDAS-VIC sensible heat flux $(H)$ 

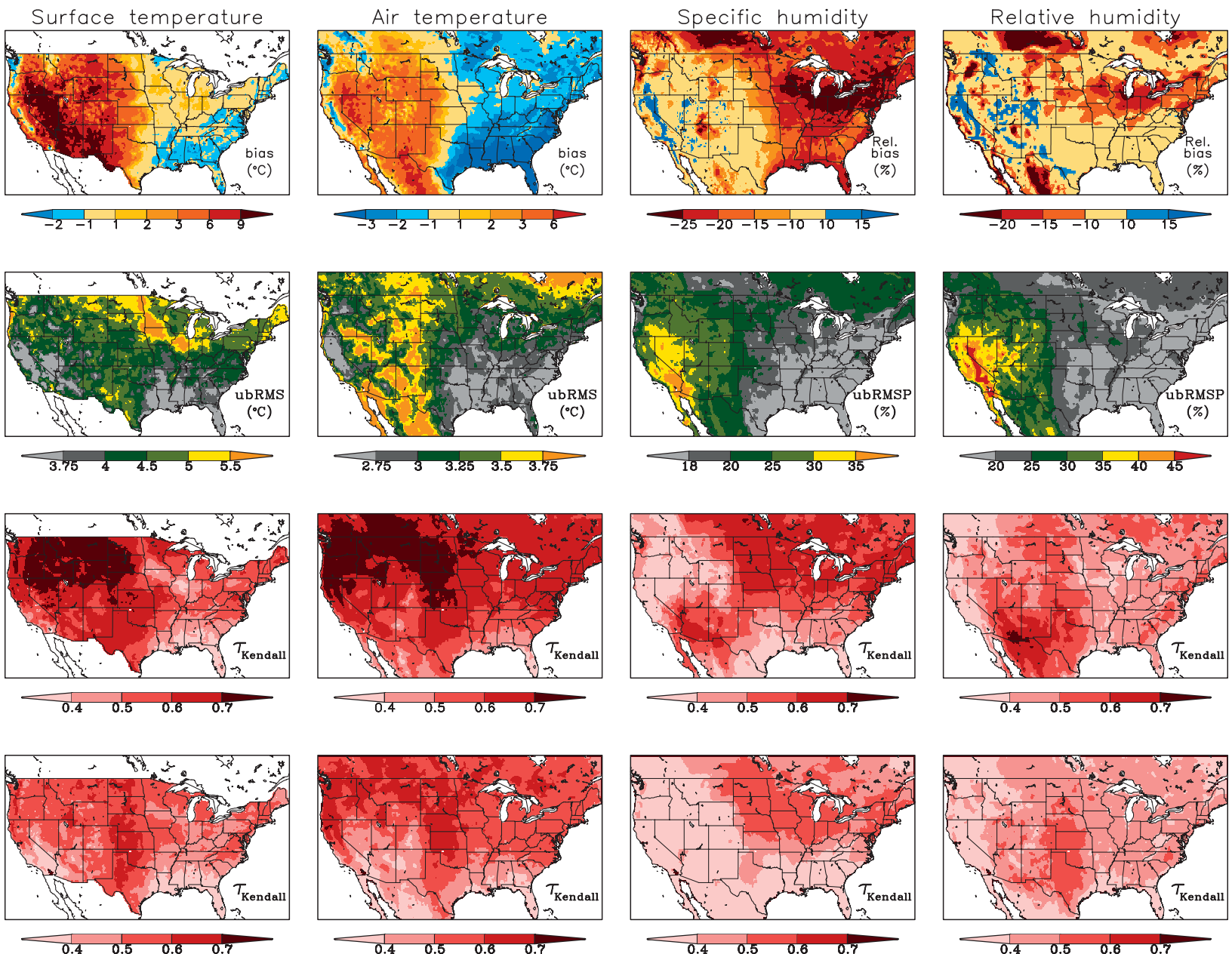

FIG. 5. Statistical summary of the AIRS-NLDAS $T_{s}, T_{a}, q$, and RH intercomparisons computed for the warm season only. (from top to bottom) Bias (RS minus modeled), ubRMS $(P)$, Kendall's $\tau$ correlation, and Kendall's $\tau$ anomaly correlation are illustrated, respectively. Out of 1165 days, the average $0.125^{\circ}$ pixel has $704 \pm 80$ AIRS-NLDAS matchups, respectively.

may be too high (and evapotranspiration too low). This corroborates the finding of Ferguson et al. (2010), which showed NLDAS upward longwave radiation (LW $\uparrow$ ) was biased low relative to International Satellite Cloud Climatology Project (ISCCP; Schiffer and Rossow 1983) $\mathrm{LW} \uparrow$. Specifically, they found mean daily differences of 19.7 and $22.7 \mathrm{~W} \mathrm{~m}^{-2}$ over the Colorado and Great basins, respectively. At mean temperatures of $15^{\circ} \mathrm{C}$, this translates into $\sim 4^{\circ} \mathrm{C}$ difference in $T_{s}$.

The remainder of this section is devoted to summarizing the comparative shifts in AIRS accuracies (relative to NLDAS) with scene (both atmospheric and surface) conditions (Fig. 7). The underlying statistics (i.e., the 5 -number summary) plus the means are provided for all boxplots in supplemental Tables S3-S6. Unless otherwise noted, 1) the difference in means between all histograms for a given condition (i.e., $\alpha_{\text {cloud }}$ ) are significant at the $p=0.05$ level and 2) all cited statistics are medians of their respective distributions across CONUS.

It is important to note that neither the geographic coverage (i.e., the number of pixels) nor the quantity of sample pairs per pixel is constant for each histogram, but in fact varies widely, even between variables. For example, there are very few pixels south of $35^{\circ} \mathrm{N}$ included in the $T_{a}<0^{\circ} \mathrm{C}$ sample or west of $97.5^{\circ} \mathrm{W}$ (except western Washington and Oregon) included in the $\alpha_{\text {cloud }}>0.6$ sample. Samples conditioned on lc class are particularly diverse in their coverage, and thus, have been addressed explicitly in Table 5. With the exception of a few land cover classes (i.e., lc03 over CONUS and lc01, lc03, and 1c05 over Africa) that were eliminated from our analyses on the basis of insufficient data, there is ample coverage for each of the remaining samples. For the total record, our analyses considered 75050 (179 380) $0.125^{\circ}$ pixels 

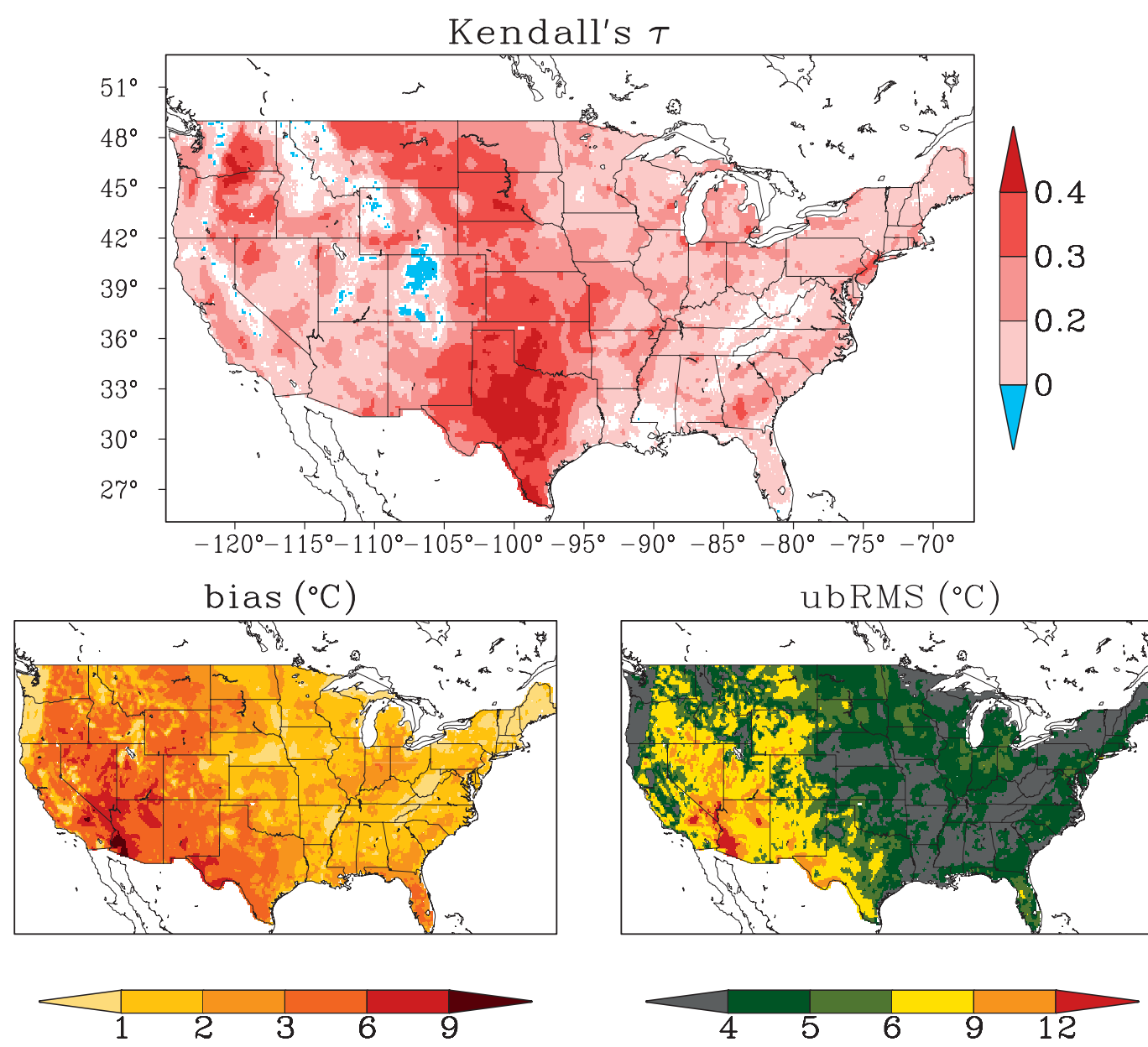

FIG. 6. Error summary of intercomparisons between the AIRS-derived $\left(T_{s}-T_{a}\right)$ and model-generated (VIC $T_{s}-$ NLDAS $T_{a}$ ) surface air temperature gradient computed for the warm season only. The minimum and maximum Kendall's $\tau$ correlation is approximately -0.2 and +0.5 , respectively. (top) Pixels for which the correlation is not statistically significant at the $p=0.01$ level are indicated by the absence of color (i.e., white).

over CONUS (Africa) each with $1700 \pm 205(470 \pm 185)$ data pairs.

\section{(i) Season}

The $T_{a}$ retrievals exhibit a negative bias $\left(-0.5^{\circ} \mathrm{C}\right)$ during the warm season and slightly positive bias $\left(+0.1^{\circ} \mathrm{C}\right)$ during the cold season. Relative to the cold season, $T_{a}$ ubRMS differences are reduced from $3.8^{\circ}$ to $2.5^{\circ} \mathrm{C}$ and $\tau$ is increased from 0.73 to 0.78 , when snow covered-only scenes are considered. This finding is reasonable, considering the presence of snow inhibits the influence of differential surface heating on the lower atmosphere, and hence, the development of thermal gradients. Conversely, snow cover diminishes the correlation between AIRS and NLDAS $T_{s}$ (0.69 to 0.46 ) and RH (0.42 to 0.13 ). The distribution of $T_{s}$ ubRMS is particularly heavy tailed (5th percentile $=3.0^{\circ} \mathrm{C}, 95$ th percentile $=6.8^{\circ} \mathrm{C}$ ) for snow covered-only retrievals, which may be the result of snow/ no-snow discrepancies between NLDAS and MODIS. The mean values of total and warm season bias in $q$ and of warm and cold season $\tau$ do not differ significantly.

\section{(ii) Surface/air temperature}

Of all sample subsets, agreement between AIRS and NLDAS $T_{s}$ reaches its minimum $(\tau=0.43)$ for subzero surface temperatures Centigrade. Under the same conditions, random errors in $T_{a}\left(4.2^{\circ} \mathrm{C}\right)$ and $q(32.6 \%)$ are at or near study maximums, which may explain the minimum in $\tau$ for RH (0.08). Correlation between AIRS and NLDAS $T_{a}$ is low at both temperature extremes $\left(T_{a}<0{ }^{\circ} \mathrm{C}, \tau=0.43 ; T_{a}>30^{\circ} \mathrm{C}, \tau=0.44\right)$, while correlation between AIRS and NLDAS $q$ is relatively 

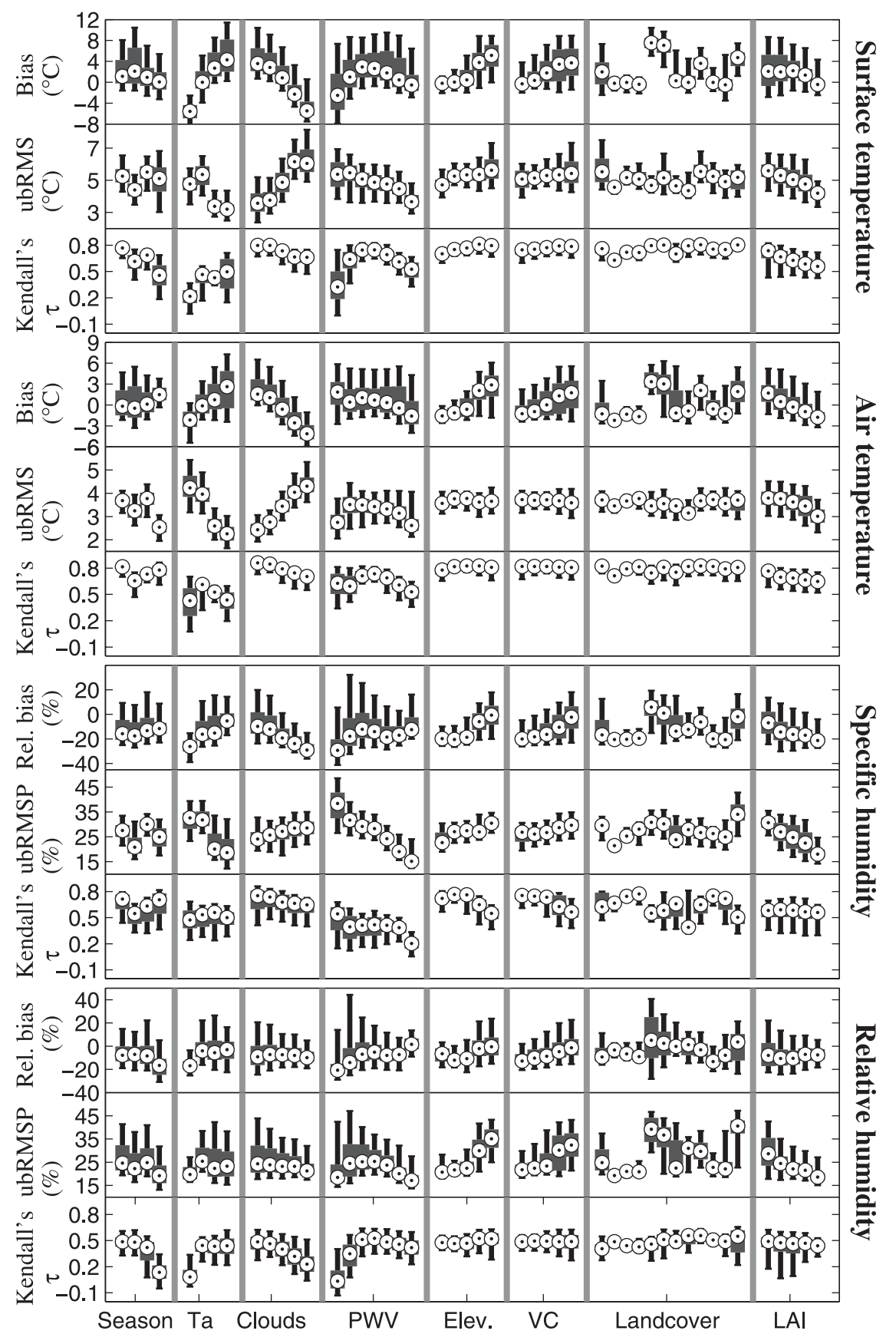

FIG. 7. Box plots of the AIRS-NLDAS $T_{s}, T_{a}, q$, and RH error statistics for a broad range of scene compositions. Each box plot corresponds with a distinct set of match-ups sampled conditionally along the gradient (generally, at quintiles) of the respective surface variable or atmospheric condition. (left to right) The record is analyzed by season: all, warm, and cold season, and snow-covered; AIRS $T_{s}$ or $T_{a}$; clouds $\left(\alpha_{\text {clouds }}\right)$; AIRS pwv; GTOPO30 mean surface elevation; SRTM vc; UMD lc: lc01, lc02, lc04, lc05, lc06, lc07, lc08, lc09, lc10, lc12, lc13, lc16; and MODIS for NACP LAI. The specific break points are detailed in Table 3. The whiskers extend to the 5th and 95th percentiles. The bull's-eye denotes the median. The figure is provided in tabular form in supplemental Tables S3-S6. 
TABLE 5. The land cover composition at $0.125^{\circ}$ for CONUS and Africa, according to the MOD12Q1 UMD classification product, listed by population density and percent coverage.

\begin{tabular}{lccc}
\hline $\begin{array}{l}\text { UMD land cover } \\
\quad \text { class }\end{array}$ & $\begin{array}{c}\text { Class } \\
\text { No. }\end{array}$ & CONUS & Africa \\
\hline $\begin{array}{l}\text { Evergreen needleleaf } \\
\quad \text { forest }\end{array}$ & 1 & $11102(14.9 \%)$ & $20(0 \%)$ \\
$\begin{array}{l}\text { Evergreen broadleaf } \\
\quad \text { forest }\end{array}$ & 2 & $559(0.8 \%)$ & $15102(8.4 \%)$ \\
$\begin{array}{l}\text { Deciduous broadleaf } \\
\quad \text { forest }\end{array}$ & 4 & $3584(4.8 \%)$ & $313(0.2 \%)$ \\
$\quad$ Mixed forests & 5 & $8891(11.9 \%)$ & $27(0 \%)$ \\
Closed shrubland & 6 & $466(0.6 \%)$ & $598(0.3 \%)$ \\
Open shrubland & 7 & $13311(17.9 \%)$ & $23559(13.1 \%)$ \\
$\quad$ Woody savannas & 8 & $1950(2.6 \%)$ & $22099(12.3 \%)$ \\
Savannas & 9 & $114(0.2 \%)$ & $33619(18.7 \%)$ \\
$\quad \begin{array}{l}\text { Grasslands } \\
\text { Croplands }\end{array}$ & 10 & $12588(16.9 \%)$ & $9902(5.5 \%)$ \\
$\quad \begin{array}{l}\text { Urban/built-up } \\
\text { Barren or sparsely }\end{array}$ & 12 & $20664(27.8 \%)$ & $4404(2.5 \%)$ \\
$\quad$ vegetated & 16 & $663(0.9 \%)$ & $256(0.1 \%)$ \\
\hline
\end{tabular}

constant with temperature. Although for warmer scenes $\left(T_{a}>20^{\circ} \mathrm{C}\right)$, ubRMSP in $q$ is reduced.

\section{(iii) Cloud albedo}

The accuracies of $T_{a}, T_{s}, q$, and to a lesser extent $\mathrm{RH}$, are all strongly linked to cloud coverage. Under clear skies $\left(\alpha_{\text {cloud }}<0.05\right)$, the AIRS-NLDAS correlation is strongest for all variables: $0.80\left(T_{s}\right), 0.86\left(T_{a}\right), 0.75(q)$, and $0.49(\mathrm{RH})$. With increasing clouds, correlation diminishes sharply and random errors also trend upward. Bias in $T_{s}$ $\left(T_{a}\right)$ changes in sign with cloud cover, from $+3.6^{\circ} \mathrm{C}$ $\left(+1.6^{\circ} \mathrm{C}\right)$ for clear skies to $-5.5^{\circ} \mathrm{C}\left(-4.1^{\circ} \mathrm{C}\right)$ for overcast conditions $\left(\alpha_{\text {cloud }}>0.6\right)$. Bias in $q$ grows in (negative) magnitude with increasing cloud coverage, from $-9.7 \%$ (clear) to $-29.0 \%$ (overcast). Traversing the gradient in $\alpha_{\text {cloud }}$, the dry (negative) bias in $q$ and coincident cold (negative) bias in $T_{\mathrm{a}}$ counteract to constrain bias in $\mathrm{RH}$ within the range of $-7.2 \%\left(0.05 \leq \alpha_{\text {cloud }}<0.2\right)$ to $-7.5 \%$ $\left(0.4 \leq \alpha_{\text {cloud }}<0.6\right)$ for typical cloud conditions. In a separate comparison (not shown), we found that the bias in $T_{a}$ for mostly cloudy $\left(0.4 \leq \alpha_{\text {cloud }}<0.6\right)$ and overcast scenes differed insignificantly from biases calculated using cold season-only retrievals for corresponding cloud types. We therefore suggest that clouds and not ambient temperature drive the seasonal error characteristics (above). Geographically, the largest differences between clear-sky and mostly cloudy $T_{s}\left(T_{a}\right)$ bias occur over parts of Nevada, California, and Oregon (approximately $40^{\circ}-44^{\circ} \mathrm{N}, 121^{\circ}-116^{\circ} \mathrm{W}$ ), with ranges of $7.6^{\circ} \mathrm{C}$ $\left(5.3^{\circ} \mathrm{C}\right)$. For $T_{s}$, an additional local maxima in clear-minuscloudy sky bias exists over western Texas $\left(30^{\circ}-34^{\circ} \mathrm{N}\right.$, $\left.104^{\circ}-101^{\circ} \mathrm{W},+8.2^{\circ} \mathrm{C}\right)$.

\section{(iv) Precipitable water vapor}

For all variables, the distribution of AIRS-NLDAS $\tau$ has the widest spread for dry atmospheres (pwv < $3.18 \mathrm{~mm}$ ). AIRS-NLDAS agreement is strongest for average pwv conditions. Accuracies for average conditions of pwv (20th-60th percentile) do not differ strongly. The impact of scene pwv on RH bias generally coincides with that of $q$ and not $T_{a}$-trending toward positive with increasing pwv. However, the trend in uncertainty of $\mathrm{RH}$ corresponds with the general trend in uncertainty of $T_{a}$.

Along a gradient of increasing pwv, uncertainty in $q$ is shown to diminish sharply: from $38.4 \%$ ( $p w v<3.18 \mathrm{~mm}$ ) to $15.1 \%$ ( $\mathrm{pwv}>34.29 \mathrm{~mm}$ ). This inverse relationship between random error and pwv seemingly contradicts the trend between random error and clouds (above). Here, we emphasize that $\alpha_{\text {cloud }}$ and pwv are not one in the same. While clouds exist at varying (and often multiple) levels of the atmosphere, pwv is driven by the lowest (and most humid) layers in the atmosphere. Therefore, pwv is strongly linked with RH, not necessarily $\alpha_{\text {cloud }}$. High pwv samples should correspond with warm and humid events/regions. Accordingly, the error characteristics should be similar to those from high $T_{a}$ samples $\left(T_{a}>\right.$ $20^{\circ} \mathrm{C}$ ), which Fig. 7 confirms.

\section{(v) Elevation}

We previously noted a direct relationship between $T_{s}$, $T_{a}$, and $T_{s}-T_{a}$ bias and mean elevation. In terms of their bias, $q$ and RH only exhibit sensitivity in the uppermost quintiles of elevation. The uncertainty in $\mathrm{RH}$ is shown to increase with elevation, coincident with diminished correlation of $q$ and increased (positive) bias in $T_{a}$.

In another experiment (not shown), we considered the same intervals in elevation for clear-sky-only retrievals in order to isolate strictly elevation-dependent effects. We found that the trends for all-sky cases (see Fig. 7) remain consistent. However, the magnitude of $T_{s}$ and $T_{a}$ (warm) bias increased significantly for all quintiles under clear skies. In terms of $T_{a}$, for example, biases for each quintile shifted from: $-1.6^{\circ}$ to $+0.4^{\circ} \mathrm{C},-1.1^{\circ}$ to $+0.5^{\circ} \mathrm{C},-0.6^{\circ}$ to $+1.2^{\circ} \mathrm{C}, 2.1^{\circ}$ to $3.7^{\circ} \mathrm{C}$, and $2.9^{\circ}$ to $5.1^{\circ} \mathrm{C}$. Likewise, for $T_{s}$, biases shifted from $-0.2^{\circ}$ to $+2.5^{\circ} \mathrm{C}$, $0^{\circ}$ to $2.5^{\circ} \mathrm{C}, 0.4^{\circ}$ to $2.9^{\circ} \mathrm{C}, 3.8^{\circ}$ to $6.2^{\circ} \mathrm{C}$, and $5.2^{\circ}$ to $8.2^{\circ} \mathrm{C}$.

\section{(vi) Vertical complexity}

Trends in error with increasing vc, were consistent with those observed for elevation (above). Given the strong correspondence between elevation and vc, this is not surprising. However, the trend is less distinct, with fatter-tailed distributions of bias for each interval of vc relative to elevation quintile counterparts. Therefore, 
we hold that elevation, and not vc, is the driving variable.

\section{(vii) UMD land cover class}

Land cover classes effectively aggregate the influences of regional climatology (atmospheric and radiative forcing), terrain, vegetation thickness (LAI), and heterogeneity (emissivity) influences on AIRS retrievals. Large bias-driven uncertainty in $T_{s}\left(+3.6^{\circ}\right.$ to $\left.+7.6^{\circ} \mathrm{C}\right)$ and $T_{a}$ $\left(+1.9^{\circ}\right.$ to $\left.+3.3^{\circ} \mathrm{C}\right)$ is shown for retrievals over shrublands (lc06, lc07), grasslands (lc10), and barren ground (lc16). Over evergreen broadleaf (lc02), deciduous broadleaf (lc04), and mixed forests (lc05), the range of $T_{s}\left(-0.4^{\circ}\right.$ to $\left.0^{\circ} \mathrm{C}\right)$ and $T_{a}\left(-2.2^{\circ}\right.$ to $\left.-1.3^{\circ} \mathrm{C}\right)$ bias is comparatively lower. However, the fact that the range (5th-95th percentile) over evergreen needleleaf forest (lc01) is nearly 4 times broader suggests that factors other than vegetation are dominating retrieval accuracy. For all variables, there are multiple pairs of landcover classes that yield insignificantly different error statistics relative to one another. The RH has the greatest uncertainty over shrubland (1c06, ubRMS $P=39.2 \%$; 1c07, ubRMS $P=$ $36.7 \%$ ) and barren ground (ubRMSP $=40.6 \%$ ). Over savannas (lc09), the AIRS and NLDAS RH exhibit the best agreement $(\tau=0.56)$, but AIRS and NLDAS $q$ are least correlated $(\tau=0.39)$. Over open shrubland (lc07), $q$ is nearly unbiased $(+1.0 \%)$.

\section{(viii) $L A I$}

Trends in bias, ubRMS, and $\tau$ are shown to be inversely related to LAI. Between the lowest and uppermost quintile of LAI, ubRMS $(P)$ is reduced from $5.6^{\circ}$ to $4.2^{\circ} \mathrm{C}, 3.8^{\circ}$ to $3.0^{\circ} \mathrm{C}, 30.7 \%$ to $18.0 \%$, and $28.7 \%$ to $18.6 \%$ in the case of $T_{s}, T_{a}, q$, and, $\mathrm{RH}$, respectively. Biases in $T_{s}\left(T_{a}\right)$ shift from $+2.1^{\circ}$ to $-0.5^{\circ} \mathrm{C}\left(+1.7^{\circ}\right.$ to $\left.-1.8^{\circ} \mathrm{C}\right)$ along the gradient of LAI. With increasing LAI, it is possible that the respective surfaces for which NLDAS and AIRS $T_{s}$ and $T_{a}$ are representative are diverging.

\section{b. Africa}

\section{1) COMPARISONS WITH NCDC}

Figures 8 and 9 are maps of the AIRS/GFS/GEOS-3NCDC error statistics over Africa. Africa has been divided into four subdomains: Sahara (SAH: $18^{\circ}-30^{\circ} \mathrm{N}$, $20^{\circ} \mathrm{W}-65^{\circ} \mathrm{E}$ ), western Africa (WAF: $12^{\circ} \mathrm{S}-18^{\circ} \mathrm{N}, 20^{\circ} \mathrm{W}-$ $22^{\circ} \mathrm{E}$ ), eastern Africa (EAF: $\left.12^{\circ} \mathrm{S}-18^{\circ} \mathrm{N}, 22^{\circ}-52^{\circ} \mathrm{E}\right)$, and southern Africa (SAF: $35^{\circ}-12^{\circ} \mathrm{S}, 10^{\circ} \mathrm{W}-52^{\circ} \mathrm{E}$ ) for which the regional mean error statistics are provided. Domainaveraged values are provided in Table 4. Analyses are limited by station coverage and density, which is especially sparse (or nonexistent) over the Sahara Desert ( $15^{\circ}-$ $30^{\circ} \mathrm{N}$ ), central Africa (i.e., Angola, Congo, Democratic
Republic of the Congo, Equatorial Guinea, Uganda, and Zambia), and Somalia. The foremost limiting factor in our analyses was the availability of $P_{\text {surf }}$, which is only reported at $75 \%$ of the stations (see Table 2).

AIRS temperature and humidity retrievals exhibit relatively higher uncertainties over the SAH and EAF, and SAH and SAF, respectively (see Fig. 8). Over SAH, $q(-30.3 \%)$ and $\mathrm{RH}(-25.6 \%)$ exhibit substantial negative biases, while $T_{a}$ is biased negatively over SAH $\left(-1.4^{\circ} \mathrm{C}\right)$ and WAF $\left(-1.6^{\circ} \mathrm{C}\right)$ and positively over EAF $\left(+4.6^{\circ} \mathrm{C}\right)$ and SAF $\left(+3.5^{\circ} \mathrm{C}\right)$. Consistent with findings over CONUS, increases in $T_{a}$ bias were found to correlate $(\tau=0.41)$ with increases in elevation (not shown). Notably, the mean slope of the relationship is of much larger magnitude $\left(+10.7^{\circ} \mathrm{C} \mathrm{km}^{-1}\right.$ above $\left.500 \mathrm{~m}\right)$. GFS $P_{\text {surf }}$ is correlated $(\tau=0.39)$ with large random errors $(4.9 \mathrm{hPa})$ over the EAF, likely due to the regions' terrain. The range in $P_{\text {surf }}$ bias and ubRMS across the four subdomains is -4.8 to +2.7 and 3.1 to $4.9 \mathrm{hPa}$, respectively. Agreement between GEOS-3 and NCDC $w$ is poor for all regions, but at a minimum over $\operatorname{EAF}(\tau=0.20)$. The range in $w$ bias and ubRMS across the four subdomains is -0.3 to +0.5 and 2.0 to $2.5 \mathrm{~m} \mathrm{~s}^{-1}$, respectively.

\section{2) COMPARISONS WITH SAF-LST}

Figure 10 illustrates results from AIRS-SEVIRI $T_{s}$ intercomparisons over Africa for the total record. For $98 \%$ of the pixels, AIRS is biased warm relative to SEVIRI. The median bias, ubRMS, and $\tau$ are $+0.5^{\circ} \mathrm{C}$, $3.9^{\circ} \mathrm{C}$, and 0.68 , respectively. The 95 th percentile of bias is $+6.4^{\circ} \mathrm{C}$. For a subdomain of the African Monsoon Multidisciplinary Analysis (AMMA) study region $\left(12.5^{\circ}-17.5^{\circ} \mathrm{N}, 2.5^{\circ} \mathrm{W}-2.5^{\circ} \mathrm{E}\right), T_{s}$ is biased by $+1.9^{\circ} \mathrm{C}$ with a ubRMS of $4.6^{\circ} \mathrm{C}$, and $\tau$ of 0.58 . The correlation between $T_{s}$ bias and elevation is not particularly strong $(\tau=$ $-0.14)$. Nevertheless, the largest biases are found above $1000 \mathrm{~m}$ in elevation, with the exception of the Sahara.

Figure 11 (which is presented quantitatively in supplemental Fig. S7) shows results from conditional sampling analyses. As with CONUS, the range in geographic coverage of samples conditioned on landcover class warranted disclosure (see Table 5). Seasonality is less straightforward when considering Africa as a whole and therefore replaced with SEVIRI quality levels: "nominal" and "below nominal." Use of nominal quality-only $\left(\mathrm{RMS}<2^{\circ} \mathrm{C}\right.$ ) SEVIRI $T_{s}$ data has the primary effect of reducing coverage to $122100\left(0.125^{\circ}\right)$ pixels located south of the $16^{\circ} \mathrm{N}$ parallel (and the Sahara). Relative to all available matchups $\left(+0.5^{\circ} \mathrm{C}\right)$, nominal quality-only sampling yields a marginally lower bias $\left(-0.1^{\circ} \mathrm{C}\right)$. However, the mean ubRMS differs by only $0.08^{\circ} \mathrm{C}$ between sampling approaches; the agreement is actually lower for the nominal quality-only sample (nominal, $\tau=0.64$; 


\section{$2 m$ air temperature Specific humidity Relative humidity}

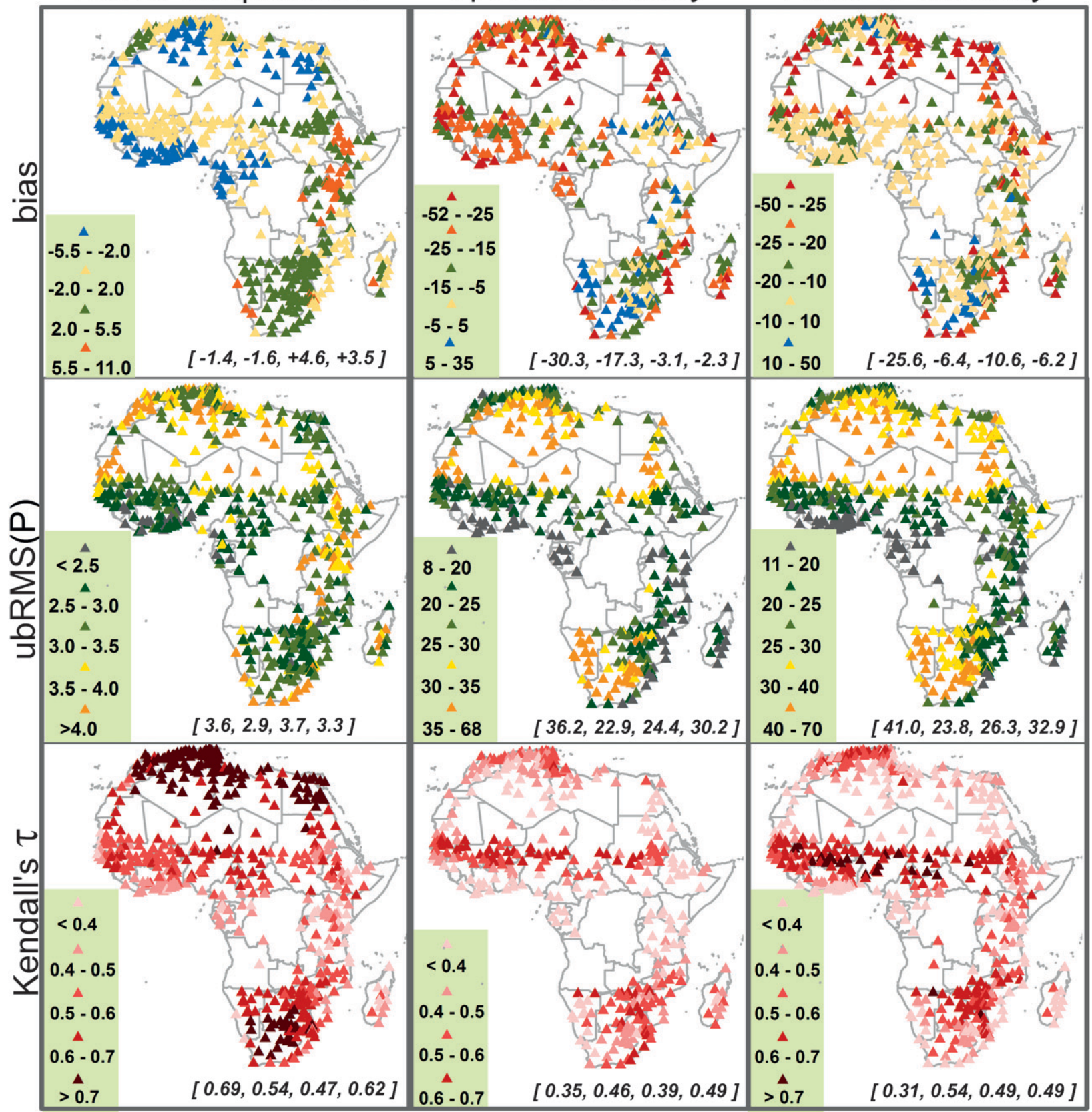

FIG. 8. Statistical summary of AIRS-NCDC $T_{a}\left({ }^{\circ} \mathrm{C}\right), q(\%)$, and RH (\%) for the total record. (top to bottom) Bias (RS minus modeled), ubRMS $(P)$, and Kendall's $\tau$ correlation are illustrated, respectively. (left to right) The bracketed values at the bottom are regional means for the Sahara $(n \sim 50)$, western Africa $(n \sim 150)$, eastern Africa $(n \sim 80)$, and southern Africa $(n \sim 150)$ domains.

all, $\tau=0.68)$. LSA-SAF applies a cloud mask, which is why there is no data available for intercomparison in overcast conditions $\left(\alpha_{\text {cloud }}>0.6\right)$.

The error characteristics derived from RS productproduct (this section) and RS product-model [section $4 \mathrm{a}(2)]$ intercomparisons were determined to be fairly robust despite the geographic diversity of the domains over which they were computed. For example (positive) bias in $T_{s}$ is reduced, random error is enhanced, and correlation weakened with increasing $\alpha_{\text {cloud }}$. With increasing LAI, bias, random error, and correlation were also reduced. Conversely, we did not observe similar trends in bias and random error as a function of pwv, elevation, or vc. Bias and ubRMS both increase with 
Surface pressure

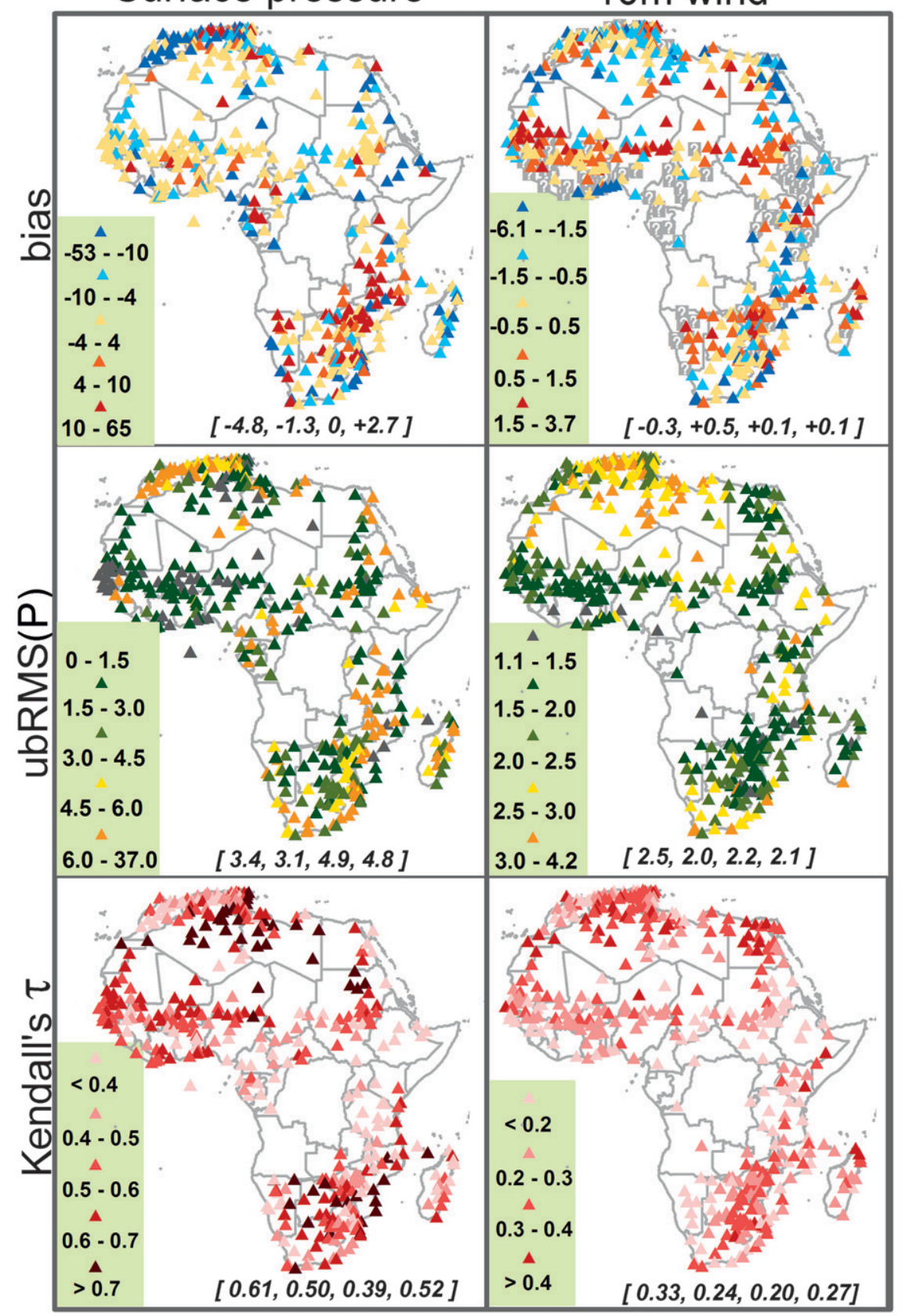

FIG. 9. As in Fig. 8, but for GFS-NCDC $P_{\text {surf }}(\mathrm{hPa})$ and GEOS-3-NCDC $w\left(\mathrm{~m} \mathrm{~s}^{-1}\right)$. Boxed gray question marks on the bias for $w$ indicate stations that were culled (see section 3 ).

pwv over Africa (unlike AIRS-NLDAS) but, correlation diminishes (like AIRS-NLDAS). In fact, the greatest overall consistency is observed in scenes of the lowest pwv $(<6.34 \mathrm{~mm})$, for which bias, ubRMS, and $\tau$ are $-0.9^{\circ} \mathrm{C}$, $2.1^{\circ} \mathrm{C}$, and 0.80 , respectively. For clear-skies, the bias is reduced $\left(-0.12^{\circ} \mathrm{C}\right)$, but we observe less overall agreement (ubRMS $=3.7^{\circ} \mathrm{C}, \tau=0.66$ ). With regard to elevation and vc, bias and ubRMS are either reduced or remain constant. The fact that the relative range in $\tau$ for each quintile of elevation, vc, and lc type is substantially broader relative to that observed over CONUS is also noteworthy. We hypothesize that both RS retrievals are similarly (and consistently, with respect to one another) affected by factors that vary with altitude (i.e., elevation, vc, and lc), but that SEVIRI is relatively more sensitive to pwv. The strongest and weakest AIRS-SEVIRI 

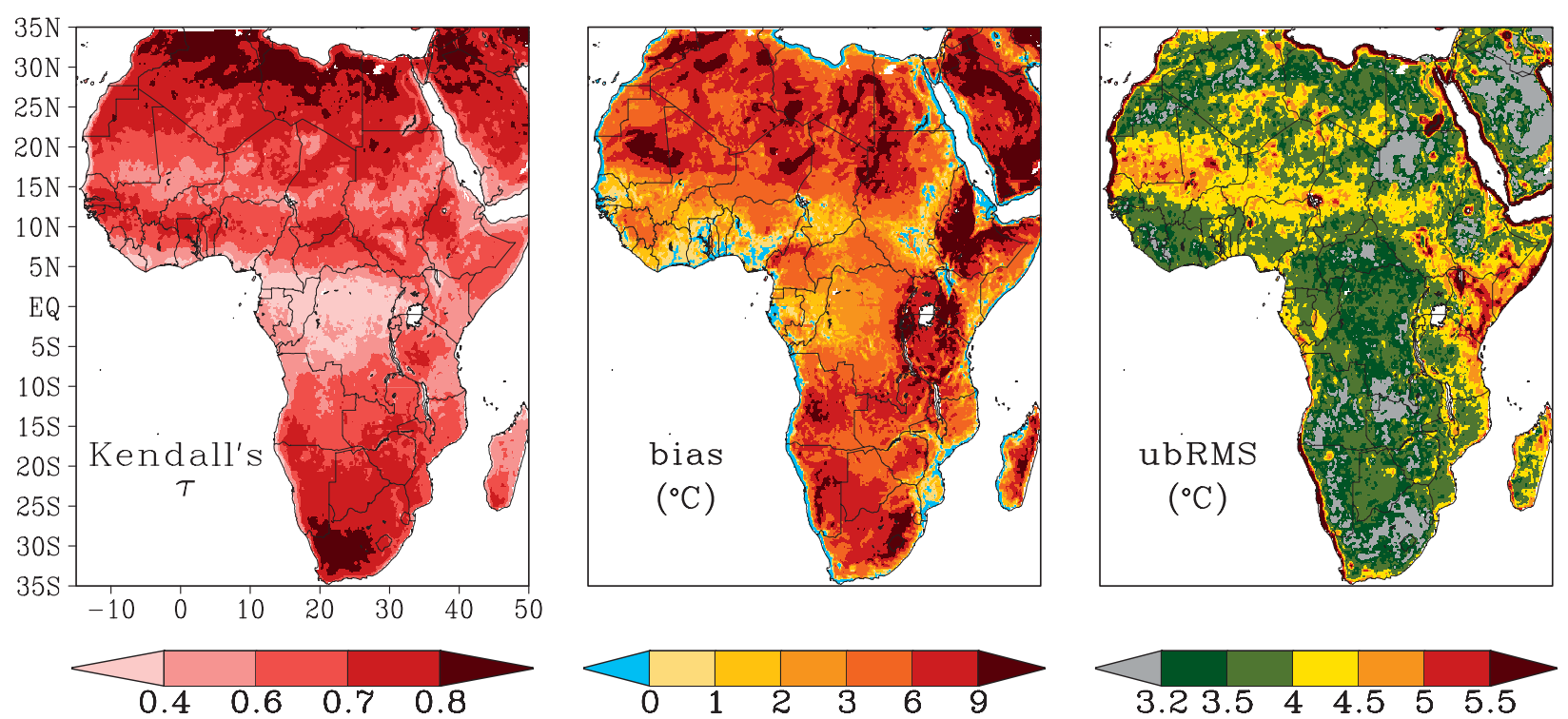

FIG. 10. Error characteristic summary from the AIRS-SEVIRI $T_{s}$ intercomparisons over Africa. The bias is defined as AIRS $T_{s}-$ SEVIRI $T_{s}$. All data pairs for which the AIRS nominal quality flag was satisfied (i.e., flag $<2$ ) were included. There were no cases of negative correlation and all correlations were significant at the $p=0.01$ level. Less than $2 \%$ of the pixels showed a negative bias of which most are located along the coastal perimeter.

correlation occurs over barren ground (0.73) and evergreen broadleaf forest $(0.39)$, respectively.

\section{Significance of error characteristics}

\section{a. Soil moisture and cloud base height}

The error characteristics identified in this study have nontrivial implications to a multitude of applications in land hydrology. In Fig. 12a, we illustrate the sensitivity of Princeton's remotely sensed X-band soil moisture (SM) retrievals (Gao et al. 2006) to errors in $T_{s}$ across the vegetation gradient. The envelope of SM sensitivity $\left(0.6 \%-3.5 \%{ }^{\circ} \mathrm{C}^{-1}\right)$ is bounded by the relative vegetation extremes of Jornada basin, New Mexico (barren) and Little River, Georgia (croplands). Figures $12 \mathrm{~b}$ and $12 \mathrm{c}$ show the sensitivity of cloud base height (LCL; refer to

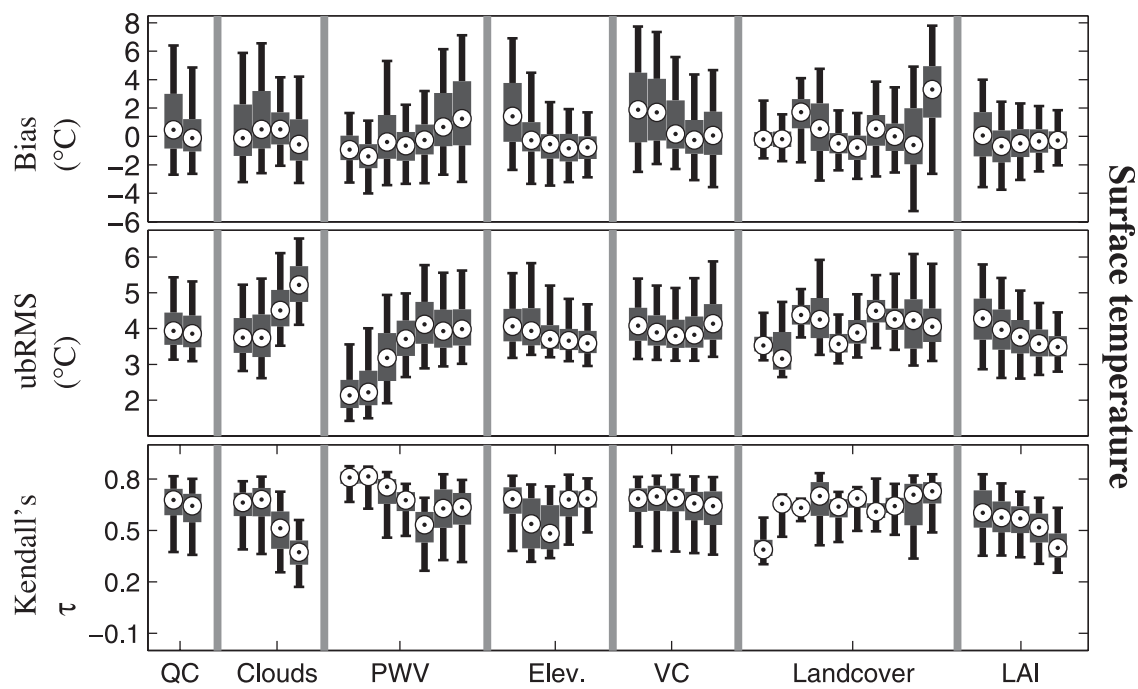

FIG. 11. As in Fig. 7, but for AIRS-SEVIRI $T_{s}$ over Africa. Note that season has been replaced by quality control (QC): AIRS-only (left, flag $<2$ ); nominal SAF (right, RMS $<2{ }^{\circ} \mathrm{C}$ ), there is no box plot for $\alpha_{\text {cloud }}>0.6$; and only lc classes $1 \mathrm{c} 02,1 \mathrm{lc} 04, \mathrm{lc} 06,1 \mathrm{c} 07, \mathrm{lc} 08$, lc09, lc $10, \mathrm{lc} 12$, lc13, and lc16 (from left to right) are included. The specific break points are detailed in Table 3 . The figure is provided in tabular form in supplemental Table S7. 

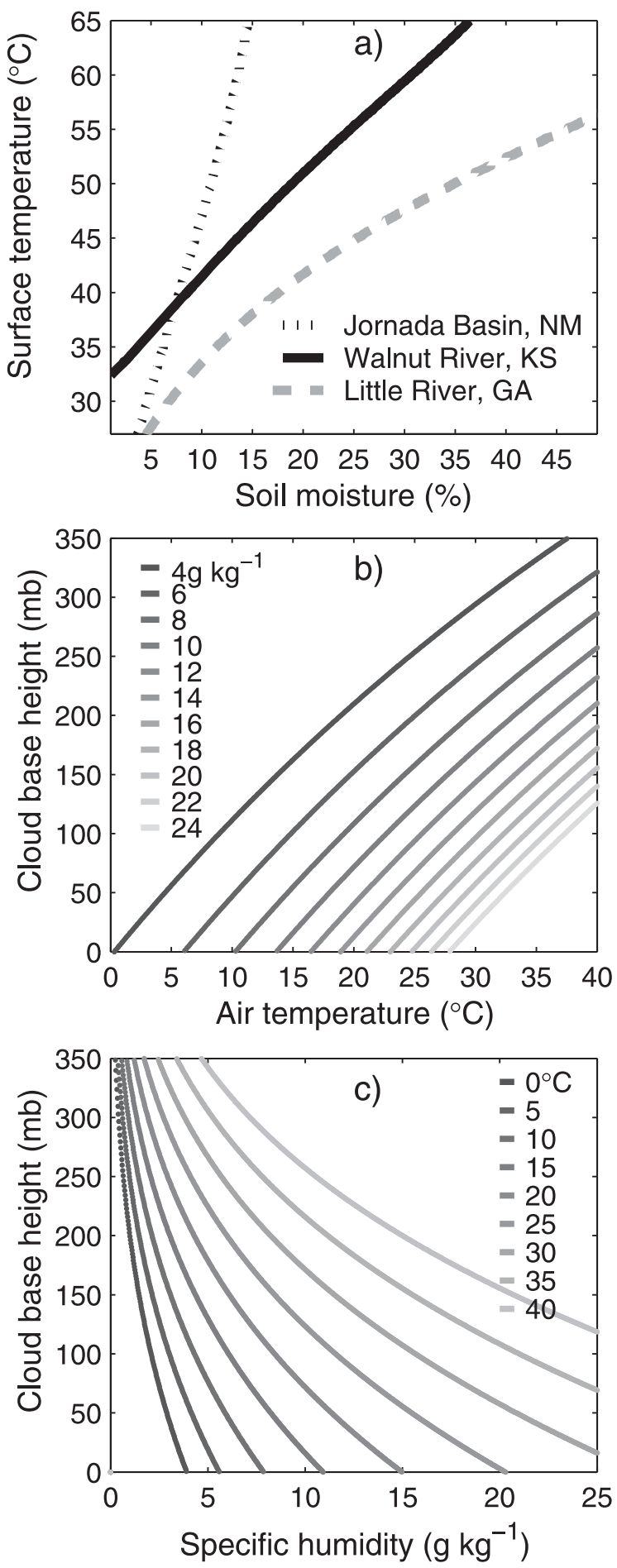

FIG. 12. (a) Sensitivity of Princeton's 10.7-GHz (Gao et al. 2006) remote sensing soil moisture (SM) retrievals to $T_{s}$ during 21-24 Jul 2003 for three sites of different vegetation water content (vwc): Jornada Basin, New Mexico $\left(32.5^{\circ} \mathrm{N}, 106.8^{\circ} \mathrm{W}\right.$; vwc $=0.1 \mathrm{~kg} \mathrm{~m}^{2}$, $\left.\Delta \mathrm{SM} / \Delta T_{s} \sim 3.5 \%{ }^{\circ} \mathrm{C}^{-1}\right)$, Walnut River, Kansas $\left(37.5^{\circ} \mathrm{N}, 96.9^{\circ} \mathrm{W}\right.$, vwc $\left.=0.8 \mathrm{~kg} \mathrm{~m}{ }^{2}, \Delta \mathrm{SM} / \Delta T_{s} \sim 1.0 \%{ }^{\circ} \mathrm{C}^{-1}\right)$, and Little River, Georgia $\left(31.6^{\circ} \mathrm{N}, 83.7^{\circ} \mathrm{W}, v w c=6.2 \mathrm{~kg} \mathrm{~m}^{2}, \Delta \mathrm{SM} / \Delta T_{s} \sim 0.6 \%{ }^{\circ} \mathrm{C}^{-1}\right)$. (b) Impact of errors in $T_{a}$ on the calculation of cloud base height over a range of humidity. (c) As in (b), but in terms of $q$.
Bolton 1980) to errors in $T_{a}\left(\sim 10 \mathrm{hPa}{ }^{\circ} \mathrm{C}^{-1}\right)$ and $q$ $\left[\sim 20 \mathrm{hPa}\left(\mathrm{g} \mathrm{kg}^{-1}\right)^{-1}\right]$. In the lower atmosphere, LCL dependence on $P_{\text {surf }}$ is negligible (not shown). By construct, RH and LCL are closely linked.

\section{b. Evapotranspiration}

Using the AIRS-NLDAS biases calculated for warm season (see Fig. 5), we assessed the impact of applying bias correction on AIRS $T_{a}, T_{s}$, and RH inputs to estimates of 4-yr (2003-06) mean warm season daytime RS $-E$ for $12,1^{\circ} \times 1^{\circ}$ regions of varying land cover and climate, and 7 major hydrological basins in CONUS (Table 6). RS-E was calculated using the modified Penman-Monteith (P-M) formulation (Mu et al. 2007), replacing GMAO meteorological inputs with inputs from AIRS and CERES, as formally described in Ferguson et al. (2010). Included in the set of study sites are five U.S. Department of Agriculture Agricultural Research Service (USDA-ARS) experimental watersheds and four BigFoot (Cohen et al. 2006; Turner et al. 2006) sites. We note here that Lamont and Little Washita, Oklahoma are contained within the North American hot spot for landatmosphere coupling (Koster et al. 2004). Daytime VIC$E$ minus the free-water (canopy) evaporation component, which is not accounted for in the $\mathrm{P}-\mathrm{M}$ framework, is included in Table 6 and serves as our best estimate of truth. With bias correction applied, RS- $E$ is reduced over the semiarid Colorado $(-23 \%)$ and arid great $(-18 \%)$ basins and enhanced by $8 \%-30 \%$ over the remaining temperate basins. Since the VIC model uses inputs from NLDAS, it is not surprising that bias-corrected RS- $E$ estimates at basin-scale shift in the direction of correspondent VIC- $E$ estimates. Additionally, we show (Table 6) that biases of \pm 0.5 and $\pm 1.0 \mathrm{~m} \mathrm{~s}^{-1}$ in $w$ can contribute an additional $-5.8 \%$ to $+3.9 \%$ and $-13.0 \%$ to $+6.4 \%$ uncertainty to basin-scale RS-E, respectively. Bias correction did impact the RS- $E$ sampling characteristics because for pixels where net radiation became negative due to the correction of $T_{s}, \mathrm{RS}-E$ was set to missing.

VIC- $E$ is not without uncertainty. Considering the degree of irrigation in Fresno and the greater Sacramento River valley, a warm season $E$ of $15.6 \mathrm{~mm}$ month $^{-1}$ seems unrealistic and is probably due to ignoring the effects of irrigation in this version of VIC. Nevertheless, the scope of this study precludes further investigation.

For Africa, assuming typical atmospheric and radiative conditions $\left[P_{\text {surf }}=977 \mathrm{hPa}, T_{s}=30.4^{\circ} \mathrm{C}, w=1.9 \mathrm{~m} \mathrm{~s}^{-1}\right.$, $R_{n}=9.56 \mathrm{MJ} \mathrm{m}^{-2}$ day $^{-1}$, momentum roughness length $\left(Z_{\text {om }}\right)=0.015 \mathrm{~m}$, water vapor roughness length = $Z_{\text {om }}(10 \mathrm{~m})^{-1}$, potential evaporation (PE) from bare soil was estimated to be $419 \mathrm{~cm} \mathrm{yr}^{-1}$ using the $\mathrm{P}-\mathrm{M}$ equation (Monteith 1964) with surface resistance set to 0. If we 
TABLE 6. The impact of bias correction of AIRS meteorology $\left(T_{a}, T_{s}, \mathrm{RH}\right.$, and $\left.w\right)$ on the 4-yr (2003-06) mean warm-season RS- $E$ $\left(\mathrm{mm}\right.$ month $\left.^{-1}\right)$ for 12 sites $\left(1^{\circ} \times 1^{\circ}\right.$ centered domains) and 7 major hydrologic basins across CONUS. RS- $E$ corresponds with Ensemble 1 in Ferguson et al. (2010).

\begin{tabular}{|c|c|c|c|c|c|c|c|c|}
\hline \multirow[b]{2}{*}{ Location } & \multirow[b]{2}{*}{ Lat } & \multirow[b]{2}{*}{ Lon } & \multirow[b]{2}{*}{$\begin{array}{l}\text { UMD* land } \\
\text { cover }\end{array}$} & \multirow[b]{2}{*}{$\begin{array}{c}\text { Daytime } \\
\text { VIC-E } \\
\left(\mathrm{mm} \text { month }^{-1}\right)\end{array}$} & \multicolumn{4}{|c|}{ Warm-season daytime RS-E (mm month ${ }^{-1}$ ) } \\
\hline & & & & & Uncorrected & $\begin{array}{l}\text { Bias } \\
\text { corrected } \\
\text { for } T_{s}, T_{a}, \\
\quad \text { and } q\end{array}$ & $\begin{array}{c}\Delta E(\%) \\
\text { with } w \pm 0.5 \\
\left(\mathrm{~m} \mathrm{~s}^{-1}\right)\end{array}$ & $\begin{array}{c}\Delta E(\%) \\
\text { with } w \pm 1.0 \\
\left(\mathrm{~m} \mathrm{~s}^{-1}\right)\end{array}$ \\
\hline \multicolumn{9}{|c|}{ USDA-ARS long-term experimental watersheds } \\
\hline Little River, GA & $31.61^{\circ} \mathrm{N}$ & $83.66^{\circ} \mathrm{W}$ & Crop & 114.5 & 80.2 & 124.4 & {$[-4.9,3.4]$} & {$[-11.0,5.9]$} \\
\hline Walnut Creek, IA & $41.02^{\circ} \mathrm{N}$ & $93.70^{\circ} \mathrm{W}$ & Crop & 111.1 & 66.6 & 77.0 & {$[-1.9,1.5]$} & {$[-4.1,2.8]$} \\
\hline Little Washita, OK & $34.95^{\circ} \mathrm{N}$ & $97.98^{\circ} \mathrm{W}$ & Grass & 72.8 & 61.8 & 65.4 & {$[-4.9,3.5]$} & {$[-11.4,6.0]$} \\
\hline Walnut Gulch, AZ & $31.72^{\circ} \mathrm{N}$ & $110.68^{\circ} \mathrm{W}$ & Oshrub & 30.6 & 37.8 & 24.8 & {$[-6.1,4.0]$} & {$[-14.0,6.8]$} \\
\hline Reynold's Creek, ID & $43.15^{\circ} \mathrm{N}$ & $116.75^{\circ} \mathrm{W}$ & Grass & 48.7 & 31.0 & 19.7 & {$[-10.2,6.7]$} & {$[-23.0,11.3]$} \\
\hline \multicolumn{9}{|l|}{ BigFoot sites } \\
\hline $\begin{array}{l}\text { Harvard Forest, MA } \\
\text { (HARV) }\end{array}$ & $42.54^{\circ} \mathrm{N}$ & $72.17^{\circ} \mathrm{W}$ & DBF & 72.5 & 87.6 & 96.6 & {$[-0.9,0.8]$} & {$[-1.9,1.4]$} \\
\hline Bondville, IL (AGRO) & $40.00^{\circ} \mathrm{N}$ & $88.29^{\circ} \mathrm{W}$ & Crop & 123.9 & 69.3 & 80.1 & {$[-1.6,1.3]$} & {$[-3.4,2.4]$} \\
\hline Park Falls, WI (CHEQ) & $45.95^{\circ} \mathrm{N}$ & $90.27^{\circ} \mathrm{W}$ & $\mathrm{DBF}$ & 57.3 & 85.6 & 92.4 & {$[-0.8,0.7]$} & {$[-1.8,1.3]$} \\
\hline Sevilleta, NM (SEVI) & $34.36^{\circ} \mathrm{N}$ & $106.70^{\circ} \mathrm{W}$ & Oshrub & 28.1 & 32.8 & 20.2 & {$[-7.5,5.1]$} & {$[-17.1,8.6]$} \\
\hline \multicolumn{9}{|l|}{ Additional sites of interest } \\
\hline Lamont, $\mathrm{OK}^{+}$ & $36.62^{\circ} \mathrm{N}$ & $97.50^{\circ} \mathrm{W}$ & Crop & 73.6 & 48.7 & 49.5 & {$[-5.3,3.7]$} & {$[-12.0,6.5]$} \\
\hline Fort Peck, MN & $48.31^{\circ} \mathrm{N}$ & $105.10^{\circ} \mathrm{W}$ & Grass & 52.5 & 37.6 & 34.7 & {$[-5.9,4.3]$} & {$[-13.2,7.7]$} \\
\hline Fresno, CA & $36.77^{\circ} \mathrm{N}$ & $119.72^{\circ} \mathrm{W}$ & Crop & 15.6 & 56.3 & 88.2 & {$[-4.5,3.0]$} & {$[-9.9,5.2]$} \\
\hline \multicolumn{9}{|l|}{ Major hydrologic basins } \\
\hline Arkansas-Red & - & - & Grass & 68.6 & 61.9 & 75.6 & {$[-3.6,2.7]$} & {$[-8.1,4.7]$} \\
\hline Colorado & - & - & Oshrub & 33.0 & 37.0 & 28.5 & {$[-5.0,3.4]$} & {$[-11.3,5.8]$} \\
\hline Great & - & - & Oshrub & 35.5 & 36.5 & 30.1 & {$[-5.8,3.9]$} & {$[-13.0,6.4]$} \\
\hline Lower Mississippi & - & - & Crop & 108.1 & 91.3 & 119.5 & {$[-3.6,2.8]$} & {$[-8.0,4.9]$} \\
\hline Upper Mississippi & - & - & Crop & 91.1 & 70.3 & 85.0 & {$[-1.7,1.4]$} & {$[-3.8,2.6]$} \\
\hline Missouri & - & - & Grass & 68.8 & 46.1 & 49.7 & {$[-4.8,3.5]$} & {$[-10.6,6.2]$} \\
\hline Ohio & - & - & Crop & 94.3 & 88.8 & 106.6 & {$[-2.3,1.8]$} & {$[-5.0,3.1]$} \\
\hline
\end{tabular}

* Crop: cropland; Grass: grassland; Oshrub: open shrubland; DBF: deciduous broadleaf forest.

+ ARM Central Facility.

apply constant daytime biases in $T_{s}$ of $+1^{\circ},+3^{\circ},+6^{\circ}$, $+9^{\circ} \mathrm{C}$, correspondent estimates of PE increase by $1 \%$, $2.9 \%, 5.5 \%$, and $7.9 \%$, respectively.

\section{Summary and conclusions}

This study represents a careful assessment of AIRSderived near-surface meteorology $\left(T_{s}, T_{a}, q, \mathrm{RH}\right.$, and $T_{s}-$ $T_{a}$ ), GFS $P_{\text {surf }}$, and GEOS- $3 w$ through intercomparison with ground measurements (NCDC), offline model output (NLDAS), and geostationary RS retrievals (SEVIRI). Our objective was threefold: 1) to quantify the mean accuracies of AIRS retrievals over an extensive domain; 2) to identify the scene conditions (atmospheric and surface) for which retrievals are particularly skillful, or conversely, prone to error; and 3) to quantify the impacts of these uncertainties on land surface hydrology variables $E$ and $\mathrm{SM}$. The nature of the task is that error estimates-and these conclusions - are invariably a product of several factors, beginning foremost with the quality screening protocol that is applied at the footprint level, the spatial interpolation technique, and ultimately, the domain and season that the analysis is conducted.

We focused this study on evaluating the $0.125^{\circ}$ gridded AIRS product [section 3a(1)] over CONUS and Africa, but for the benefit of our discussion, also provided summary error statistics at the AIRS footprint $(13.5 \mathrm{~km})$ scale (Fig. A1, supplemental Figs. S1-S5) over CONUS. Through conditional sampling, we explicitly investigated retrieval errors across gradients in ambient surface and air temperature, cloud albedo, total column precipitable water vapor/ice, elevation, topographic complexity, land cover class, leaf area index, snow cover, and season (Figs. 7 and 11). Under the best retrieval conditions-clear skies-the interquartile range of AIRS-NLDAS RMS errors were found to be $3.7^{\circ}$ $7.7^{\circ} \mathrm{C}\left(T_{s}\right), 2.3^{\circ}-4.6^{\circ} \mathrm{C}\left(T_{a}\right), 26.9 \%-27.2 \%(q)$, and $26.2 \%-32.2 \%(\mathrm{RH})$. Over Africa, AIRS-SEVIRI $T_{s}$ 
intercomparisons yielded an interquartile RMS range of $3.6^{\circ}-4.8^{\circ} \mathrm{C}$ for clear skies and significantly lower $\left(2.4^{\circ}-\right.$ $2.6^{\circ} \mathrm{C}$ ) for atmospherically dry (pwv $<6.34 \mathrm{~mm}$ ) conditions. Using data matchups at $\sim 1500$ NCDC ground stations, we found mean AIRS/GFS/GEOS-3-NCDC (NLDAS-NCDC) RMS errors of $3.8^{\circ} \mathrm{C}\left(2.3^{\circ} \mathrm{C}\right), 32.0 \%$ (21.3\%), 30.7\% (24.4\%), $12.1 \mathrm{hPa}(9.3 \mathrm{hPa})$, and $1.9 \mathrm{~m} \mathrm{~s}^{-1}$ $\left(2.0 \mathrm{~m} \mathrm{~s}^{-1}\right)$ for $T_{a}, q, \mathrm{RH}, P_{\text {surf }}$, and $w$, respectively. Notably, the accuracy of NLDAS forcing has only previously been verified for a 3-yr period (1996-99) over the SGP (Luo et al. 2003; Mitchell et al. 2004). Using 500 NCDC stations in Africa, mean AIRS/GFS/GEOS-3NCDC RMS errors were found to be $4.6^{\circ} \mathrm{C}\left(T_{a}\right), 33.8 \%$ $(q), 34.3 \%(\mathrm{RH}), 11.0 \mathrm{hPa}\left(P_{\text {surf }}\right)$, and $2.4 \mathrm{~m} \mathrm{~s}^{-1}(w)$.

In general, AIRS $q$ and $T_{a}$ were shown to be biased dry (CONUS: $-10.3 \%$; Africa: $-12.4 \%$ ) and (slightly) warm (CONUS: $+0.2^{\circ} \mathrm{C}$; Africa: $+1.0 \%$ ). Previously, dry biases were also noted in AIRS-GPS pwv comparisons over CONUS (Raja et al. 2008). The interquartile ranges in AIRS-NLDAS $T_{a}$ and $q$ RMS (above) encompass prior estimates of $2.8^{\circ} \mathrm{C}$ (January) and $3.4^{\circ} \mathrm{C}$ (July) for China (W.H. Gao et al. 2008) and 27\% $(P=$ $800 \mathrm{hPa}$ ) globally (Divakarla et al. 2006). Biases in $T_{a}$ were shown to correlate well with elevation (above $500 \mathrm{~m}$ ), as best illustrated by the east (negative) to west (positive) gradient in bias over CONUS (Fig. 1). This supports similar findings of Jones et al. (2010) and Gao et al. (2008b) with AIRS and Lakshmi et al. (2001) with TOVS. We suggest that this correlation is induced by changes in several variables with altitude, including lc class, LAI, and humidity. Because of the combined effects of errors in $T_{a}$ and $q$, RH had a much lower bias (CONUS: $-1.4 \%$; Africa: $-10.5 \%$ ). There is a distinctly negative-biased band of RH correspondent with the Midwest "corn belt" (Fig. 1).

Collectively, our findings indicate that the gridded near-surface AIRS variables are not meeting the $2^{\circ}-3^{\circ} \mathrm{C}$ $\left(T_{s}\right), 1.0^{\circ} \mathrm{C}\left(T_{a}\right)$ and $20 \%(q$ and $\mathrm{RH})$ RMS accuracy criterion set forth by the AIRS Science Team. Of course, within the CONUS and Africa subdomains, there exists substantial spatial diversity in error characteristics. For example, mean errors are clearly affected by the west CONUS and Sahara Africa. Moreover, the NLDAS and NCDC datasets do have inherent uncertainty. Mitchell et al. (2004) determined that NLDAS-VIC $T_{s}$ had an RMS of $4.5^{\circ} \mathrm{C}$ relative to the Geostationary Operational Environmental Satellite (GOES) over the north-central CONUS during July 1999. And this study's findings [section $4 \mathrm{a}(2)$ ], taken jointly with those of Ferguson et al. (2010), suggest that NLDAS-VIC $T_{s}$ is biased cold over the west CONUS.

AIRS provides a unique set of variables for land surface hydrological studies that are ideally available coincidentally (in time and space) with radiation and microwave measurements from the CERES and the Advanced Microwave Scanning Radiometer- Earth Observing System (AMSRE-E) sensors, also on board NASAs Aqua. In section 5, we quantified the impact of errors in $T_{s}$ on microwave soil moisture retrievals and estimates of $P E$, errors in $T_{a}$ and $q$ on estimates of LCL, and errors in $T_{s}, T_{a}, \mathrm{RH}$, and $w$ on estimates of warmseason daytime RS-E. These limited examples derive from a much larger set of applications for which there is a clear need for confidence/error estimates to quantify input-driven uncertainty. Despite challenges to skillful retrievals, the strength of RS remains to be that it provides accurate patterns of real-life land surface variability, which is currently missing from land hydrology and atmospheric analyses (McCabe et al. 2008).

Throughout this study, an underlying question was whether beyond CONUS, in data-scarce regions such as Africa, could AIRS uncertainty be quantified a priori as a function of scene atmospheric and surface conditions? Our conclusion is that although this may be feasible, multiple explanatory variable are necessary and it will likely require regional and temporally varying regression relationships that may only be obtainable through initial AIRS versus truth intercomparisons.

Only the ascending $(\sim 1330$ local time $)$ retrievals have been evaluated. In the future, our framework may be transferred to nighttime retrievals, as well as expanded globally. Given insights gained from this study, we would divide the analysis by river basin, as we have done here for the footprint-scale intercomparisons (supplemental Figs. S2-S5), and vary the search radius of the interpolation scheme as a function of mean pressure difference with distance (see supplemental Table S2).

Acknowledgments. This research was jointly supported through the author's NASA Earth and Space Science Fellowship NNX08AU28H: "Understanding Hydrologic Sensitivity and Land-Atmosphere Coupling through Space-Based Remote Sensing" and NASA Grant NNG04GQ32G: "A Terrestrial Evaporation Product Using MODIS Data" (Eric F. Wood, PI). We gratefully acknowledge the efforts of Pedro Diegues at LSA-SAF (see online at http://landsaf.meteo.pt/) who provided the SEVIRI/Meteosat data. AIRS level 2 data products were obtained from the NASA Goddard Earth Sciences Data and Information Services Center via FTP (airspar1u.ecs.nasa.gov). CERES SSF products were obtained from the Atmospheric Science Data Center at the NASA Langley Research Center (see online at http:// eosweb.larc.nasa.gov/). The SRTM version 4 90m DEM was obtained from the International Centre for Tropical Agriculture (CIAT; see online at http://srtm.csi.cgiar.org). 

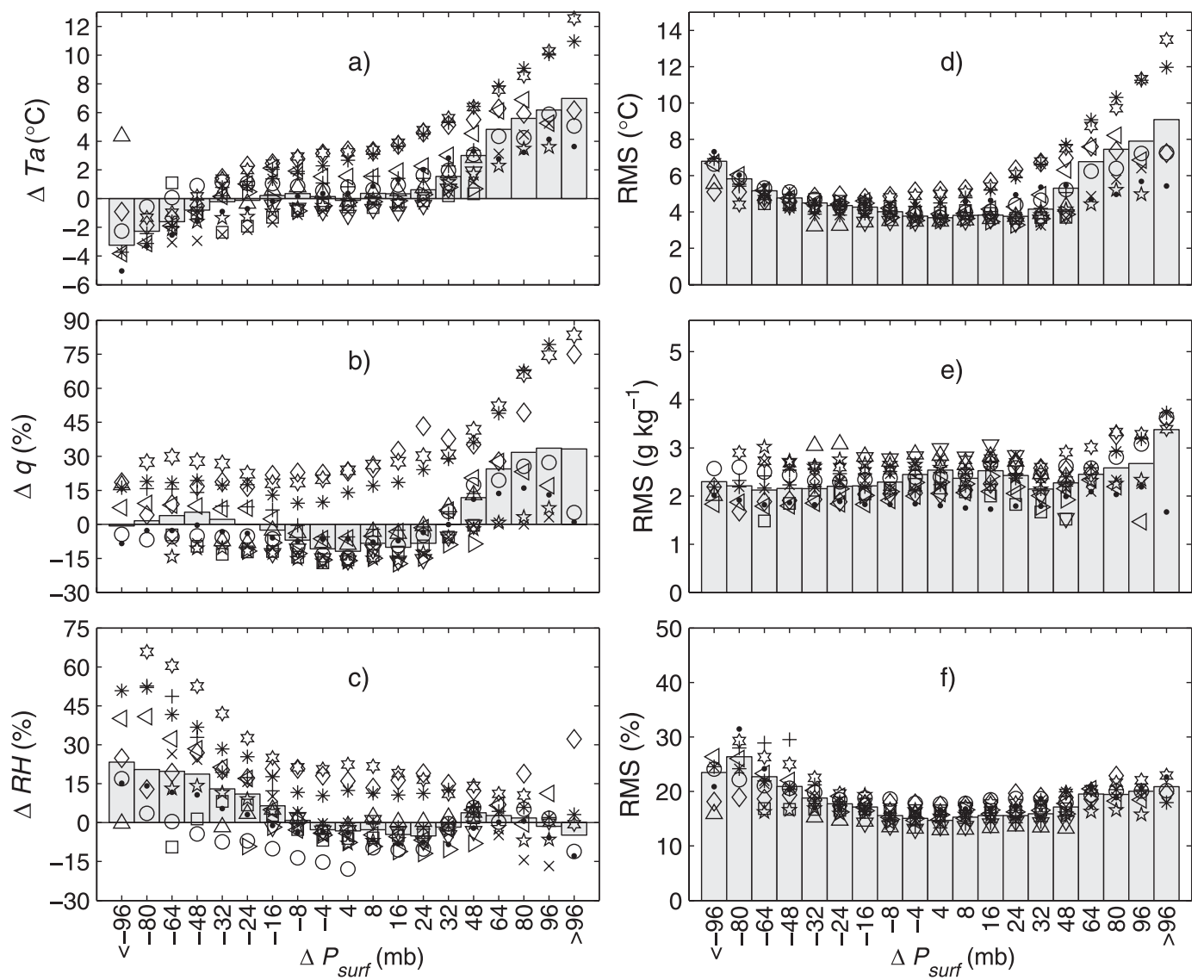

\begin{tabular}{|c|c|c|c|c|c|c|c|c|c|c|c|c|c|c|}
\hline & CON & & + & $-R$ & 0 & & * & COL & - & PNW & $x$ & $M-A$ & $\square$ & GLK \\
\hline$\diamond$ & GR & $\triangle$ & $T-G$ & $\nabla$ & LMISS & D & & UMISS & $\triangleleft$ & MISSO & th & $\mathrm{OH}$ & {$[3$} & RIO \\
\hline
\end{tabular}

FIG. A1. AIRS footprint error characteristics over CONUS as a function of footprint to station (GFS - NCDC) pressure differences calculated using the total record (2002-08, or $n \sim 9000000)$. (a)-(c) The bias (AIRS - NCDC) of $T_{a}$, relative bias of $q$, and relative bias of RH is illustrated, respectively. (d)-(f) The RMS of $T_{a}, q$, and RH is illustrated, respectively. The CONUS mean response is indicated by the bars; symbols indicate basin-scale responses. Basin errors are only plotted for a particular bin if greater than 500 data pairs are available. Notably, station distribution is not uniform (see Fig. 1). The mean pressure difference varies with distance across basins (see supplemental Table S2). The following abbreviations were applied: A-R: Arkansas-Red; CAL: California; COL: Colorado; PNW: Pacific Northwest; M-A: Mid-Atlantic; GLK: Great Lakes; GR: Great; T-G: Texas-Gulf; LMISS: Lower Mississippi; UMISS: Upper Mississippi; MISSO: Missouri; OH: Ohio; RIO: Rio Grande.

The GTOPO30 DEM was obtained from the U.S. Geological Survey's Center for Earth Resources Observation and Science (EROS) Data Center (see online at http:// edc.usgs.gov/). The MOD12Q1 land cover dataset was obtained from the NASA-developed Earth Observing System (EOS) Clearinghouse (ECHO) through the NASA Warehouse Inventory Search Tool (WIST; see online at https://wist.echo.nasa.gov). MODIS snow products were obtained through the National Snow and Ice Data Center (NSIDC; see online at http://nsidc.org) Distributed Active Archive Center. The MRT is maintained and distributed by the NASA Land Processes Distributed Active Archive Center (LPDAAC; see online at https://lpdaac.usgs.gov).

\section{APPENDIX}

The use of AIRS level 2 version 5 quality flags for $T_{s}$, $T_{a}, q$, and RH is summarized herein: $T_{s}$ : Only AIRS footprint $T_{s}$ (TSurfStd) that satisfied Qual_Surf $<2.0$ were accepted. In fact, the highest-quality designation assigned to AIRS $T_{s}$ over land is 1.0 or "good" quality.

$T_{a}:$ If PGood $\geq P_{\text {surf }}$, the AIRS footprint $T_{a}$ (TSurfAir) was accepted. AIRS temperature retrievals at or above PGood are included in the generation of AIRS level $3,1^{\circ} \times 1^{\circ}$ gridded products. If $\mathrm{PGood} \geq$ $P_{\text {surf, }}$, the version 4 legacy quality flag, Qual_ Temp_Profile_Bot, was also found to be $<2.0$ and 
vice versus. Only $18 \%$ of all retrievals where PGood $\geq P_{\text {surf }}$ satisfied the condition PBest $\geq P_{\text {surf }}$.

$q$ and RH: If Qual_H2O $<2.0$ and PGood $\geq P_{\text {surf }}$, the

AIRS near-surface level temperatures (TAirSup) and humidity (H2OCDSup) were accepted. For all cases, if Qual_H2O $<2.0$, then PGood $\geq P_{\text {surf }}$. Conversely, Qual_H2O $<2.0$ is not satisfied in $4.7 \%$ of the cases where PGood $\geq P_{\text {surf }}$.

We note that for each of the variables, the AIRSX2SUP product does include error estimates; namely, TSurfStdErr $\left(T_{s}\right)$, TAirStdErr $\left(T_{a}\right)$, and H2OCDSupErr ( $q$ and $\mathrm{RH})$. We were reluctant to constrain the sample set (and risk imparting a significant sampling bias) by applying arbitrary error thresholds on error estimates of unprescribed confidence and ultimately elected not to use these. For example, over the $\sim 1500$ NCDC stations in CONUS, we determined that $26 \%(15 \%)$ of all retrievals where PGood (PBest) is $\geq P_{\text {surf }}$ would not satisfy TSurfStdErr $<5.0^{\circ} \mathrm{C}$. Retrieval error characteristics can be investigated at the gridded product level (as in this study), or alternatively at footprint scale. We have investigated the bias and RMS error characteristics of footprint (prior to interpolation) values as a function of pressure difference (Fig. A1), season, pwv (totH2OStd), AIRS IR cloud fraction (TotCld_4_CCfinal), and CERES $\alpha_{\text {cloud }}$ these later analyses are illustrated in supplemental Figs. S2-S5.

\section{REFERENCES}

Alsdorf, D., P. Bates, D. Lettenmaier, N. Mognard, D. Moller, and E. Rodriguez, 2008: What will SWOT measurements and products look like? Eos, Trans. Amer. Geophys. Union, 89 (Fall Meeting Suppl.), Abstract H311-03.

Andersson, E., and Coauthors, 2007: Analysis and forecast impact of the main humidity observing systems. Quart. J. Roy. Meteor. Soc., 133, 1473-1485.

Andreadis, K. M., and D. P. Lettenmaier, 2006: Assimilating remotely sensed snow observations into a macroscale hydrology model. Adv. Water Resour., 29, 872-886.

Asrar, G., and D. J. Dokken, 1993: Earth Observing System (EOS) reference handbook. National Aeronautics and Space Administration, Earth Science Support Office, Document Resource Facility, 145 pp.

Aumann, H. H., and Coauthors, 2003: AIRS/AMSU/HSB on the Aqua mission: Design, science objectives, data products, and processing systems. IEEE Trans. Geosci. Remote Sens., 41, $253-264$.

Betts, A. K., J. H. Ball, A. C. M. Beljaars, M. J. Miller, and P. A. Viterbo, 1996: The land surface-atmosphere interaction: A review based on observational and global modeling perspectives. J. Geophys. Res., 101, 7209-7225.

Bindlish, R., W. T. Crow, and T. J. Jackson, 2009: Role of passive microwave remote sensing in improving flood forecasts. IEEE Geosci. Remote Sens. Lett., 6, 112-116.
Birkett, C. M., 1998: Contribution of the TOPEX NASA radar altimeter to the global monitoring of large rivers and wetlands. Water Resour. Res., 34, 1223-1239.

Bolton, D., 1980: The computation of equivalent potential temperature. Mon. Wea. Rev., 108, 1046-1053.

Bowling, L. C., and Coauthors, 2003: Simulation of high-latitude hydrological processes in the Torne-Kalix basin: PILPS phase 2(e) - 1: Experiment description and summary intercomparisons. Global Planet. Change, 38, 1-30.

Chahine, M. T., 1974: Remote sounding of cloudy atmospheres. Part I: Single cloud layer. J. Atmos. Sci., 31, 233-243.

_- 1977: Remote sounding of cloudy atmospheres. Part II: Multiple cloud formations. J. Atmos. Sci., 34, 744-757.

- and Coauthors, 2001: AIRS-Team retrieval for core products and geophysical parameters: Level 2 Algorithm Theoretical Basis Document. JPL D-17006, NASA GSFC, 198 pp. [Available online at http://eospso.gsfc.nasa.gov/eos_homepage/ for_scientists/atbd/docs/AIRS/atbd-airs-L2.pdf.]

—_, and Coauthors, 2006: Improving weather forecasting and providing new data on greenhouse gases. Bull. Amer. Meteor. Soc., 87, 911-926.

Cohen, W. B., and Coauthors, 2006: MODIS land cover and LAI collection 4 product quality across nine sites in the western hemisphere. IEEE Trans. Geosci. Remote Sens., 44, 1843-1857.

Cosgrove, B. A., and Coauthors, 2003: Real-time and retrospective forcing in the North American Land Data Assimilation System (NLDAS) project. J. Geophys. Res., 108, 8842, doi:10.1029/ 2002JD003118.

Crow, W. T., and E. F. Wood, 2003: The assimilation of remotely sensed soil brightness temperature imagery into a land surface model using Ensemble Kalman filtering: A case study based on ESTAR measurements during SGP97. Adv. Water Resour., 26, 137-149.

— , and J. D. Bolten, 2007: Estimating precipitation errors using spaceborne surface soil moisture retrievals. Geophys. Res. Lett., 34, L08403, doi:10.1029/2007GL029450.

—, R. Bindlish, and T. J. Jackson, 2005: The added value of spaceborne passive microwave soil moisture retrievals for forecasting rainfall-runoff partitioning. Geophys. Res. Lett., 32, L18401, doi:10.1029/2005GL023543.

_ - G. J. Huffman, R. Bindlish, and T. J. Jackson, 2009: Improving satellite-based rainfall accumulation estimates using spaceborne surface soil moisture retrievals. J. Hydrometeor., 10, 199-212.

Darnell, W. L., W. F. Staylor, S. K. Gupta, N. A. Ritchey, and A. C. Wilber, 1992: Seasonal-variation of surface radiation budget derived from International Satellite Cloud Climatology Project C1 data. J. Geophys. Res., 97, 15 741-15 760.

Davey, C. A., and R. A. Pielke, 2005: Microclimate exposures of surface-based weather stations-Implications for the assessment of long-term temperature trends. Bull. Amer. Meteor. Soc., 86, 497-504.

Dirmeyer, P. A., 2006: The hydrologic feedback pathway for landclimate coupling. J. Hydrometeor., 7, 857-867.

Divakarla, M. G., C. D. Barnet, M. D. Goldberg, L. M. McMillin, E. Maddy, W. Wolf, L. H. Zhou, and X. P. Liu, 2006: Validation of Atmospheric Infrared Sounder temperature and water vapor retrievals with matched radiosonde measurements and forecasts. J. Geophys. Res., 111, D09S15, doi:10.1029/ 2005JD006116.

Ek, M. B., and A. A. M. Holtslag, 2004: Influence of soil moisture on boundary layer cloud development. J. Hydrometeor., 5, 86-99. 
Ferguson, C. R., J. Sheffield, E. F. Wood, and H. Gao, 2010: Quantifying uncertainty in a remote sensing-based estimate of evapotranspiration over continental USA. Int. J. Remote Sens., 14, 3821-3865.

Fetzer, E. J., 2006: Preface to special section: Validation of Atmospheric Infrared Sounder Observations. J. Geophys. Res., 111, D09S01, doi:10.1029/2005JD007020.

Frappart, F., S. Calmant, M. Cauhope, F. Seyler, and A. Cazenave, 2006: Preliminary results of ENVISAT RA-2-derived water levels validation over the Amazon basin. Remote Sens. Environ., 100, 252-264.

Freitas, S. C., I. F. Trigo, J. M. Bioucas-Dias, and F. M. Gottsche, 2010: Quantifying the uncertainty of land surface temperature retrievals from SEVIRI/Meteosat. IEEE Trans. Geosci. Remote Sens., 48, 523-534.

Friedl, M. A., 1996: Relationships among remotely sensed data, surface energy balance, and area-averaged fluxes over partially vegetated land surfaces. J. Appl. Meteor., 35, 2091-2103.

Ganguly, S., A. Samanta, M. A. Schull, N. V. Shabanov, C. Milesi, R. R. Nemani, Y. Knyazikhin, and R. B. Myneni, 2008: Generating vegetation leaf area index Earth system data record from multiple sensors. Part 2: Implementation, analysis and validation. Remote Sens. Environ., 112, 4318-4332.

Gao, F., and Coauthors, 2008: An algorithm to produce temporally and spatially continuous MODIS-LAI time series. IEEE Geosci. Remote Sens. Lett., 5, 60-64.

Gao, H., E. F. Wood, T. J. Jackson, M. Drusch, and R. Bindlish, 2006: Using TRMM/TMI to retrieve surface soil moisture over the southern United States from 1998 to 2002. J. Hydrometeor., 7, 23-38.

Gao, W. H., F. S. Zhao, Y. F. Xu, and X. Feng, 2008: Validation of the surface air temperature products retrieved from the atmospheric infrared sounder over China. IEEE Trans. Geosci. Remote Sens., 46, 1783-1789.

Garcia-Haro, F. J., S. Sommer, and T. Kemper, 2005: A new tool for variable multiple endmember spectral mixture analysis (VMESMA). Int. J. Remote Sens., 26, 2135-2162.

Guo, Z. C., and Coauthors, 2006: GLACE: The Global LandAtmosphere Coupling Experiment. Part II: Analysis. J. Hydrometeor., 7, 611-625.

Gupta, S. K., D. P. Kratz, P. W. Stackhouse, and A. C. Wilber, 2001: The Langley Parameterized Shortwave Algorithm(LPSA) for surface radiation budget studies (Version 1.0). NASA/TP-2001211272, 31 pp.

Hall, D. K., and G. A. Riggs, 2007: Accuracy assessment of the MODIS snow products. Hydrol. Processes, 21, 1534-1547.

,,-- V. V. Salomonson, N. E. DiGirolamo, and K. J. Bayr, 2002: MODIS snow-cover products. Remote Sens. Environ., 83, 181-194.

Hansen, M. C., R. S. Defries, J. R. G. Townshend, and R. Sohlberg, 2000: Global land cover classification at $1 \mathrm{~km}$ spatial resolution using a classification tree approach. Int. J. Remote Sens., 21, 1331-1364.

Holmes, T., R. A. M. De Jeu, M. Owe, and A. J. Dolman, 2009: Land surface temperature from $\mathrm{Ka}$ band $(37 \mathrm{GHz})$ passive microwave observations. J. Geophys. Res., 114, D04113, doi:10.1029/2008JD010257.

Hong, Y., R. F. Adler, A. Negri, and G. J. Huffman, 2007: Flood and landslide applications of near real-time satellite rainfall products. Nat. Hazards, 43, 285-294.

Hsu, K. L., X. G. Gao, S. Sorooshian, and H. V. Gupta, 1997: Precipitation estimation from remotely sensed information using artificial neural networks. J. Appl. Meteor., 36, 1176-1190.
— H. V. Gupta, X. G. Gao, and S. Sorooshian, 1999: Estimation of physical variables from multichannel remotely sensed imagery using a neural network: Application to rainfall estimation. Water Resour. Res., 35, 1605-1618.

Huffman, G. J., R. F. Adler, E. Stocker, D. Bolvin, and E. Nelkin, 2003: Analysis of TRMM 3-hourly multi-satellite precipitation estimates computed in both real and post-real time. Preprints, 12th Conf. on Satellite Meteorology and Oceanography, Long Beach, CA, Amer. Meteor. Soc., P4.11.

— , and Coauthors, 2007: The TRMM Multisatellite Precipitation Analysis (TMPA): Quasi-global, multiyear, combined-sensor precipitation estimates at fine scales. J. Hydrometeor., 8, $38-55$.

Huntington, T. G., 2006: Evidence for intensification of the global water cycle: Review and synthesis. J. Hydrol., 319, 83-95.

Jones, L. A., C. R. Ferguson, J. S. Kimball, Z. Zhang, S. K. Chan, K. C. McDonald, E. G. Njoku, and E. F. Wood, 2010: Satellite microwave remote sensing of daily land surface air temperature minima and maxima from AMSR-E: Comparison with AIRS/AMSU. IEEE J. Selected Topics Appl. Earth Observ. Remote Sens., 3, 111-123.

Jonsson, P., and L. Eklundh, 2004: TIMESAT-A program for analyzing time-series of satellite sensor data. Comput. Geosci., 30, 833-845.

Joyce, R. J., J. E. Janowiak, P. A. Arkin, and P. P. Xie, 2004: CMORPH: A method that produces global precipitation estimates from passive microwave and infrared data at high spatial and temporal resolution. J. Hydrometeor., 5, 487-503.

Kabsch, E., F. S. Olesen, and F. Prata, 2008: Initial results of the land surface temperature (LST) validation with the Evora, Portugal ground-truth station measurements. Int. J. Remote Sens., 29, 5329-5345.

Kelly, R. E., A. T. Chang, L. Tsang, and J. L. Foster, 2003: A prototype AMSR-E global snow area and snow depth algorithm. IEEE Trans. Geosci. Remote Sens., 41, 230-242.

Knuteson, R. O., S. A. Ackerman, H. Revercomb, and D. Tobin, 2008: Comparison of NASA AIRS and MODIS land surface temperature and infrared emissivity measurements from the EOS Aqua platform. Int. Workshop on the Retrieval and Use of Land Surface Temperature: Bridging the Gaps, Asheville, NC, NOAA/NCDC.

Koster, R. D., M. J. Suarez, R. W. Higgins, and H. M. Van den Dool, 2003: Observational evidence that soil moisture variations affect precipitation. Geophys. Res. Lett., 30, 1241, doi:10.1029/2002GL016571.

__ , and Coauthors, 2004: Regions of strong coupling between soil moisture and precipitation. Science, 305, 1138-1140.

— , and Coauthors, 2006: GLACE: The Global Land-Atmosphere Coupling Experiment. Part I: Overview. J. Hydrometeor., 7, 590-610.

Kumar, S. V., R. H. Reichle, C. D. Peters-Lidard, R. D. Koster, X. W. Zhan, W. T. Crow, J. B. Eylander, and P. R. Houser, 2008: A land surface data assimilation framework using the land information system: Description and applications. Adv. Water Resour., 31, 1419-1432.

Lakshmi, V., K. Czajkowski, R. Dubayah, and J. Susskind, 2001: Land surface air temperature mapping using TOVS and AVHRR. Int. J. Remote Sens., 22, 643-662.

Lott, N., 2004: The quality control of the integrated surface hourly database. Preprints, 14th Conf. on Applied Climatology, Seattle, WA, Amer. Meteor. Soc., 7.8.

- R. Baldwin, and P. Jones, 2001: The FCC integrated surface hourly database: A new resource of global climate data. 
National Climatic Data Center Tech. Rep. 2001-01, U.S. Department of Commerce, National Environmental Satellite Data and Information Service, National Climatic Data Center, $42 \mathrm{pp}$.

Lu, H., T. Koike, H. Fujii, T. Ohta, and K. Tamagawa, 2009: Development of a physically-based soil moisture retrieval algorithm for spaceborne passive microwave radiometers and its application to AMSR-E. J. Remote Sens. Soc. Japan, 29, 253-261.

Luo, L. F., and E. F. Wood, 2007: Monitoring and predicting the 2007 U.S. drought. Geophys. Res. Lett., 34, L22702, doi:10.1029/2007GL031673.

_ , and Coauthors, 2003: Validation of the North American Land Data Assimilation System (NLDAS) retrospective forcing over the southern Great Plains. J. Geophys. Res., 108, 8843, doi:10.1029/2002JD003246.

Madeira, C., 2002: Generalized split-window algorithm for retrieving land-surface temperature from MSG/SEVIRI data. Proc. Land Surface Analysis SAF Training Workshop, Lisbon, Portugal, European Organisation for the Exploitation of Meteorological Satellites, 42-47.

Margulis, S. A., and D. Entekhabi, 2003: Variational assimilation of radiometric surface temperature and reference-level micrometeorology into a model of the atmospheric boundary layer and land surface. Mon. Wea. Rev., 131, 1272-1288.

McCabe, M. F., E. F. Wood, R. Wójcik, M. Pan, J. Sheffield, H. Gao, and H. Su, 2008: Hydrological consistency using multi-sensor remote sensing data for water and energy cycle studies. Remote Sens. Environ., 112, 430-444.

Mitchell, K. E., and Coauthors, 2004: The multi-institution North American Land Data Assimilation System (NLDAS): Utilizing multiple GCIP products and partners in a continental distributed hydrological modeling system. J. Geophys. Res., 109, D07S90, doi:10.1029/2003JD003823.

Monteith, J. L., 1964: Evaporation and environment: The state of movement of water in living organisms. Symp. Soc. Exp. Biol., 19, 205-234.

Mu, Q., F. A. Heinsch, M. Zhao, and S. W. Running, 2007: Development of a global evapotranspiration algorithm based on MODIS and global meteorology data. Remote Sens. Environ., 111, 519-536.

Njoku, E. G., T. J. Jackson, V. Lakshmi, T. K. Chan, and S. V. Nghiem, 2003: Soil moisture retrieval from AMSR-E. IEEE Trans. Geosci. Remote Sens., 41, 215-229.

NWC-SAF, 2010: Algorithm Theoretical Basis Document for cloud products (CMa-PGE01 v3.0, CT-PGE02 v2.0, CTTHPGE03 v2.1). SAF/NWC/CDOP/MFL/SCI/ATBD/01, Issue 3, Rev. 0, 17 May 2010, 87 pp. [Available online at http:// www.nwcsaf.org/indexScientificDocumentation.html.]

Olsen, E. T., 2007: AIRS/AMSU/HSB version 5 level 2 product levels, layers and trapezoids. Jet Propulsion Laboratory, California Institute of Technology, Pasadena, CA, 11 pp.

Pan, M., and E. F. Wood, 2009: A multiscale ensemble filtering system for hydrologic data assimilation. Part II: Application to land surface modeling with satellite rainfall forcing. $J$. $H y$ drometeor., 10, 1493-1506.

Peres, L. F., and C. C. DaCamara, 2005: Emissivity maps to retrieve land-surface temperature from MSG/SEVIRI. IEEE Trans. Geosci. Remote Sens., 43, 1834-1844.

Raja, M. K. R. V., S. I. Gutman, J. G. Yoe, L. M. McMillin, and J. Zhao, 2008: The validation of AIRS retrievals of integrated precipitable water vapor using measurements from a network of ground-based GPS receivers over the contiguous United States. J. Atmos. Oceanic Technol., 25, 1245-1246.
Reichle, R. H., W. T. Crow, and C. L. Keppenne, 2008: An adaptive ensemble Kalman filter for soil moisture data assimilation. Water Resour. Res., 44, W03423, doi:10.1029/ 2007WR006357.

Reuter, H. I., A. Nelson, and A. Jarvis, 2007: An evaluation of voidfilling interpolation methods for SRTM data. Int. J. Geogr. Info. Sci., 21, 983-1008.

Schiffer, R. A., and W. B. Rossow, 1983: The International Satellite Cloud Climatology Project (ISCCP): The first project of the World Climate Research Programme. Bull. Amer. Meteor. Soc., 64, 779-784.

Schmetz, J., P. Pili, S. Tjemkes, D. Just, J. Kerkmann, S. Rota, and A. Ratier, 2002: An introduction to Meteosat Second Generation (MSG). Bull. Amer. Meteor. Soc., 83, 977-992.

Sheffield, J., C. R. Ferguson, T. J. Troy, E. F. Wood, and M. F. McCabe, 2009: Closing the terrestrial water budget from satellite remote sensing. Geophys. Res. Lett., 36, L07403, doi:10.1029/2009GL037338.

Shuttleworth, W. J., 1988: Macrohydrology-The new challenge for process hydrology. J. Hydrol., 100, 31-56.

Sorooshian, S., K. L. Hsu, X. Gao, H. V. Gupta, B. Imam, and D. Braithwaite, 2000: Evaluation of PERSIANN system satellitebased estimates of tropical rainfall. Bull. Amer. Meteor. Soc., 81, 2035-2046.

Stackhouse, P. W., S. K. Gupta, S. J. Cox, M. Chiacchio, and C. Mikovitz, 2000: The WCRP/GEWEX Surface Radiation Budget Project Release 2: An assessment of surface fluxes at 1 degree resolution. IRS 2000: Current Problems in Atmospheric Radiation, W. L. Smith and Y. M. Timofeyev, Eds., 4 pp.

Susskind, J., P. Piraino, L. Rokke, T. Iredell, and A. Mehta, 1997: Characteristics of the TOVS Pathfinder Path A dataset. Bull. Amer. Meteor. Soc., 78, 1449-1472.

— C. D. Barnet, and J. M. Blaisdell, 1998: Determination of atmospheric and surface parameters from simulated AIRS/AMSU/ HSB sounding data: Retrieval and cloud clearing methodology. Remote Sens.: Inver. Prob. Nat. Hazards, 21, 369-384.

,-- , and -2003 : Retrieval of atmospheric and surface parameters from AIRS/AMSU/HSB data in the presence of clouds. IEEE Trans. Geosci. Remote Sens., 41, 390-409.

,,,--- L. Iredell, F. Keita, L. Kouvaris, G. Molnar, and M. Chahine, 2006: Accuracy of geophysical parameters derived from Atmospheric Infrared Sounder/Advanced Microwave Sounding Unit as a function of fractional cloud cover. J. Geophys. Res., 111, D09S17, doi:10.1029/2005JD006272.

, J. Blaisdell, L. Iredell, and F. Keita, 2010: Improved temperature sounding and quality control methodology using AIRS/AMSU data: The AIRS science team Version 5 retrieval algorithm. IEEE Trans. Geosci. Remote Sens., in press, doi:10.1109/TGRS.2010.2070508.

Tapley, B. D., S. Bettadpur, M. Watkins, and C. Reigber, 2004: The gravity recovery and climate experiment: Mission overview and early results. Geophys. Res. Lett., 31, L09607, doi:10.1029/ 2004GL019920.

Tobin, D. C., and Coauthors, 2006: Atmospheric Radiation Measurement site atmospheric state best estimates for Atmospheric Infrared Sounder temperature and water vapor retrieval validation. J. Geophys. Res., 111, D09S14, doi:10.1029/2005JD006103.

Trigo, I. F., L. F. Peres, C. C. DaCarnara, and S. C. Freitas, 2008a: Thermal land surface emissivity retrieved from SEVIRI/ Meteosat. IEEE Trans. Geosci. Remote Sens., 46, 307-315. , I. T. Monteiro, F. Olesen, and E. Kabsch, 2008b: An assessment of remotely sensed land surface temperature. J. Geophys. Res., 113, D17108, doi:10.1029/2008JD010035. 
Troy, T. J., E. F. Wood, and J. Sheffield, 2008: An efficient calibration method for continental-scale land surface modeling. Water Resour. Res., 44, W09411, doi:10.1029/ 2007WR006513.

Tucker, C. J., J. E. Pinzon, M. E. Brown, D. A. Slayback, E. W. Pak, R. Mahoney, E. F. Vermote, and N. El Saleous, 2005: An extended AVHRR 8-km NDVI dataset compatible with MODIS and SPOT vegetation NDVI data. Int. J. Remote Sens., 26, 4485-4498.

Turner, D. P., and Coauthors, 2006: Evaluation of MODIS NPP and GPP products across multiple biomes. Remote Sens. Environ., 102, 282-292.

Walker, J. P., and P. R. Houser, 2001: A methodology for initializing soil moisture in a global climate model: Assimilation of near-surface soil moisture observations. J. Geophys. Res., 106, 11 761-11 774.

Wan, Z. M., and J. Dozier, 1996: A generalized split-window algorithm for retrieving land-surface temperature from space. IEEE Trans. Geosci. Remote Sens., 34, 892-905.

Wofsy, S. C., and R. C. Harriss, 2002: The North American carbon program (NACP). NACP Committee of the U.S. Interagency Carbon Cycle Science Program Rep., UGCR Program, 56 pp.

Zhang, Y. C., W. B. Rossow, A. A. Lacis, V. Oinas, and M. I. Mishchenko, 2004: Calculation of radiative fluxes from the surface to top of atmosphere based on ISCCP and other global data sets: Refinements of the radiative transfer model and the input data. J. Geophys. Res., 109, D19105, doi:10.1029/ 2003JD004457. 